\title{
Photo-degradation of four different organic dyes in green synthesized chromium nanoparticles by leaf extracts of ocimum basilicum-lamiaceae (Thiru neetru pathilai)
}

\author{
G.Vanitha $^{\mathrm{a}}$, R.Manikandan ${ }^{\mathrm{a}, \mathrm{b}}$, A.Prakasam ${ }^{\mathrm{a}, \mathrm{c}}$, M.D.Navinkumar ${ }^{\mathrm{a}, \mathrm{d}}$ \\ K.Sathiyamoorthi ${ }^{\mathrm{e}}$, B.Dhinakaran ${ }^{\text {a* }}$ \\ ${ }^{a} P G$ and Research Department of Physics, Government Arts College, Chidambaram, Tamilnadu, \\ India- 608001. \\ ${ }^{b}$ Munna College of Education college Parangipettai, Tamil nadu, India-608502 \\ ${ }^{c} P G \&$ Research Department of Physics, Aringar Anna Arts College, Vilupuram, Tamilnadu, India-605602 \\ ${ }^{d}$ Vivekanadan College of Education, Puducherry, India-605008 \\ ${ }^{e} P G$ and Research Department of Chemistry, Government Arts College,Chidambaram, Tamilnadu, \\ India- 608001 . \\ *Corresponding author e-mail: dhina.spectra@gmail.com
}

\begin{abstract}
Nanotechnology is an escalating field, which has a growing impact in each and every sector. There are many ways for synthesizing nanoparticles but biosynthetic route of nanoparticle synthesis is emerging as a new and safer alternative to the conventional methods. Ocimum basilicum is an age old herb native to Southeast Asia and Central African countries. These plants are generally known to be used in different cuisines world-wide. The aroma emitted from the leaves and the twigs of the fresh and dried plants are well known to have insect repellent property. Estragole, citronellal, limonene and nerolidol are the natural volatile compounds present in the basil leaves which acts as repellents. This plant is also widely used as a scent through which it netted its title Queen (basileus) of aromatic herbs. In present study the Green synthesis of Chromium oxide nanoparticles have been synthesized by Ocimum Basilicum-Lamiaceae (Thiru Neetru Pathilai).This method is completely a green method, free from toxic and harmful solvent. The formation of chromium oxide nanoparticles confirmed by UV-Visible spectrophotometer (UV-Vis), and Fourier transform infrared spectroscope (FTIR). The FTIR measurement was carried out to identify possible functional contain the natural product, responsible for efficient stabilization of chromium oxide nanoparticle.
\end{abstract}

Keyword: Ocimum Basilicum-Lamiaceae, Green synthesis, CrNPs, UV, FTIR, DLS, SEM \& EDS, TEM and Photo degradation

\section{INDRODUCTIONS}

In recent years nanotechnology gained utmost importance in industrial, pharmaceutical, environmental and health care applications due to their unique physical and chemical characteristics [1]. The chromium $(\mathrm{Cr})$ is an essential trace element and plays a vital role in carbohydrate metabolism as a structural component of glucose tolerance factor (GTF) by potentiating the action of insulin, which increases the absorption of glucose molecules from circulation into peripheral tissues and improves its utilization, thereby inhibiting gluconeogenes is from non-carbohydrate sources [2,3].Crisalso involved in the metabolism of lipid, protein, and nucleic acid [4-11]. But, the quantum of its requirement for an aquatic organism and its toxicity threshold has to be balanced. $\mathrm{Cr}$ occurs in the natural environment, as hexavalent $(\mathrm{Cr} 6+)$ and trivalent $\left(\mathrm{Cr}^{3+}\right)$ forms [12-14]. $\mathrm{The}^{\mathrm{Cr}}{ }^{6+}$ compounds are extensively 
used and released into the environment by diverse industries, chrome plating, leather tanning, textile dyes, copy machine toner, wood preservatives, and stainless steel casting and welding. The $\mathrm{Cr}^{3+}$ form in different salts (e.g., chloride, niacin, picolinate, and polynicotinate) is used as a dietary supplement and micronutrient [15-18].
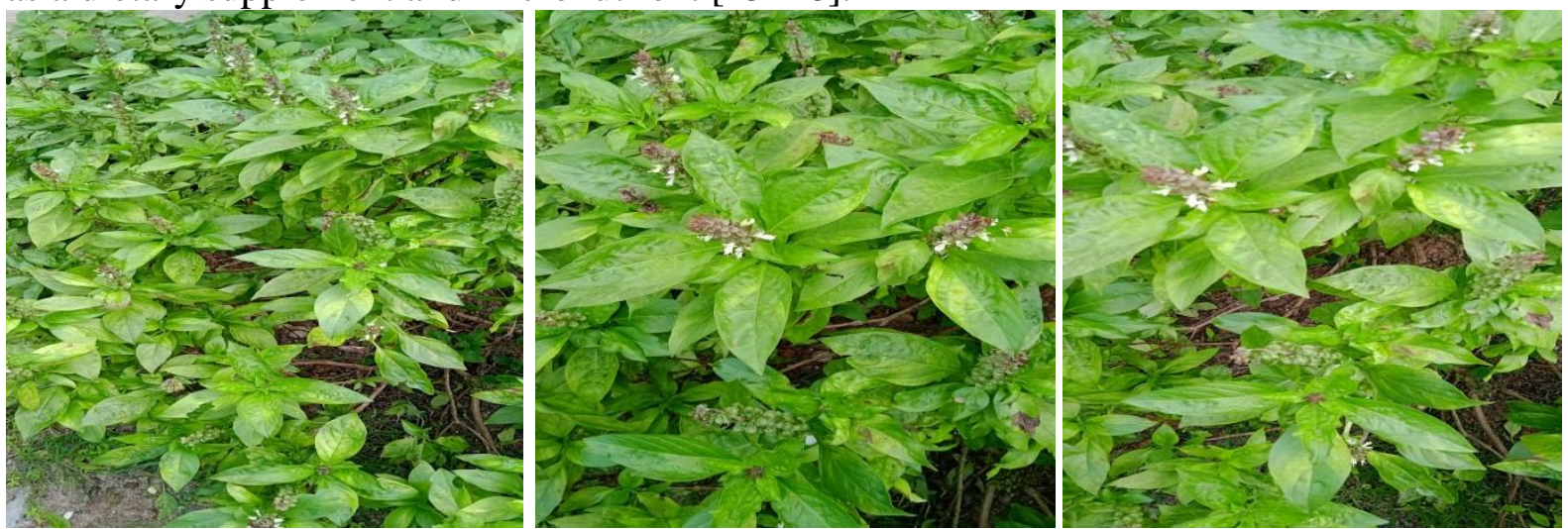

Figure:1 Plant of Ocimum basilicum Lamiaceae(Thiru neetru pathilai)

Ocimum basilicum Lamiaceae. Belongs to family Lamiaceae. The family Lamiaceae comprises the most employed medicinal plants as a worldwide source of spices and also as a consolidated source of extracts. The chemical composition of sweet basil essential oil has been investigated and by now more than 200 chemical components [19-28] have been reported from many regions of the world. The chemical constituents showed the presence of monoterpene hydrocarbons, oxygenated monoterpene, sesquiterpene hydrocarbons, oxygenated sesquiterpene, triterpene, flavanoids, and aromatic compounds. In the present study, chromium nanoparticle (CrNP) were green synthesized from $\mathrm{K}_{2} \mathrm{Cr}_{2} \mathrm{O}_{7}$ using aqueous leaves extract of Basilicum-Lamiaceae (Thiru Neetru Pathilai, Sweet Basil) as reducing agent. Then, the green synthesized CrNPs [29-30] were characterized through preliminary analysis such as $\mathrm{pH}$ and TDS, UV-visible spectroscopy, Fourier transform infrared spectroscopy (FT-IR), DLS (Dynamic light scattering), SEM, EDS and TEM analysis. The synthesized chromium nanoparticles are applied to four different organic dyes such as methyl orange(MO), methyl red(MR), methyl blue(MB) and Alizarin red(AR) dyes for photocatalytic degradation activity.

\section{Material and Methods}

\subsection{Collection of Sample}

Fresh Ocimum Basilicum-Lamiaceae (Thiru Neetru Pathilai) leaves were collected from botanical garden, Department of Botany, Government arts college, Chidambaram. Leaves were washed in three times thoroughly by running ordinary tap water (OTW), then washed two times with double distilled water (DDW) to remove any dust particles on the leaves, washed leaves were allowed to dry in air at room temperature. The dried leaves were grained and powdered by using electric mixer. This powder was used to prepare the leaves extracts

\subsection{Chemicals, Solvents and Starting Materials}

De-ionized water, whatmann $1 \neq$ and whatmann $41 \neq$ filter papers, Potassium di chromate Ethyl alcohol, sodium hydroxide pellets, Hydrochloric acids, sulphuric acid and other chemicals were purchased from Merck (India) Ltd. All chemicals were used without further purification.

\subsection{Instruments and equipment}

Electric oven, Magnetic stirrer (REMI $2 \mathrm{MLH}$ ), E-1 portable TDS \& EC meter, pH-009(I)A pen type $\mathrm{pH}$ meter, sterilized $250 \mathrm{ml}$ separating funnels, sterilized conical flasks, 
sterilized $400 \mathrm{ml}$ beakers, watch glasses, $7^{\prime}$ ' funnels, glass rods, and $10 \mathrm{ml}$ measuring cylinders,

\subsection{Preparation of Ocimum Basilicum-Lamiaceae Leaves Extract}

5 grams of powdered Ocimum Basilicum-Lamiaceae (Thiru Neetru Pathilai) (OBL) leaves with $50 \mathrm{~mL}$ of double-distilled water (DDW) taken in the $250 \mathrm{~mL}$ round bottomed flask, water condenser fitted and fix the running tap water then heated for $20 \mathrm{~min}$ at $80^{\circ} \mathrm{C}$. Then the extract was filtered with Whatman $1 \neq$ filter paper. The filtrate was used to the further green synthesis of process

\subsection{Synthesis of Chromium nanoparticles (CrNPs)}

For the synthesis of CrNPs by reducing potassium di chromate ( M.F: $\mathrm{K}_{2} \mathrm{Cr}_{2} \mathrm{O}_{7}, \mathrm{MW}$ : $294.19 \mathrm{~g} / \mathrm{mol}$ ) using OBL leaf extract. To achieve this intention, $180 \mathrm{~mL}$ of homogenous solution of potassium di chromate is steadily mixed with $20 \mathrm{~mL}$ of OBL leaves extract followed by continuous heating $\left(70{ }^{\circ} \mathrm{C}\right)$ and stirring at $500 \mathrm{rpm}$ for $2 \mathrm{~h}$ at magnetic stirrer with heating instrument, to achieve precipitate containing final solution, The red orange colour reactant solution is turn to brownish red colour. The obtained brownish red colour solution was centrifuged at $4000 \mathrm{rpm} / 20 \mathrm{~min}$. Supernatant was discarded and pellet containing CrNPs was carefully washed 3 times[29] with double distilled water (DDW) to remove uninvolved phyto-constituent and other chemicals. The obtained wet precipitate is dried, collects and stored the airtight clicklock tube. Finally, CrNPs were steadily characterized.

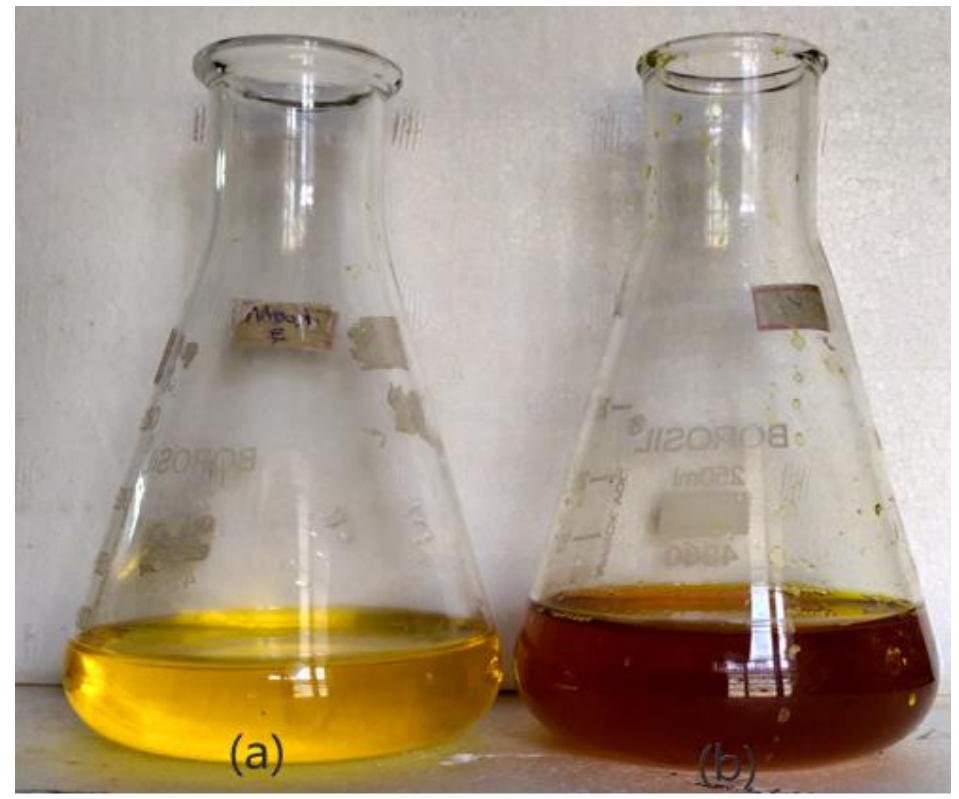

Fig:2. (a) $1 \mathrm{mM} \mathrm{K} \mathrm{Cr}_{2} \mathrm{O}_{7}$ solution , (b)CrNPs

\section{Characterization of $\mathrm{Cr}_{2} \mathrm{O}_{3} \mathrm{NPs}$}

The preliminary analysis were report in this articles such as $\mathrm{pH}$ and TDS this are measured by digital meters, absorption spectra (Hitachi U-2001) of green synthesized $\mathrm{Cr}_{2} \mathrm{O}_{3} \mathrm{NPs}$ were analyzed at different wavelengths between 200 and $800 \mathrm{~nm}$. The possible functional group of green synthesized Chromium oxide nanoparticles $\left(\mathrm{Cr}_{2} \mathrm{O}_{3} \mathrm{NPs}\right)$ were observed by Fourier transform infrared spectroscopy (Perkin Elmer make model Spectrum $\mathrm{Rx} 1)$ with a range of $4000 \mathrm{~cm}^{-1}-400 \mathrm{~cm}^{-1}$. The average size measured by Dynamic light scattering(DLS) analysis, The crystallinity and phase purity of the $\mathrm{Cr}_{2} \mathrm{O}_{3} \mathrm{NPs}$ nanoparticles was investigated by the powdered X-ray diffraction (XRD) using $\mathrm{K} \alpha$ radiation into the 
angular range of $20^{\circ}<20>80^{\circ}$ a (Model-D8 Advance, BRUKER, Germany). The morphology of the sample was analysed by Scanning Electron Microscope (SEM, Hi-tech model-S 3400n) and TEM- Transmission Electron Microscope (Hitachi H-7100). EDAX (Energy dispersive X-ray), was carried out to prove the occurrence of pure elemental Chromium Oxide particles. The photo-degradation of Methylene Blue (MB), Methyl Orange, Methyl red and Allizarin red dyes were performed with $\mathrm{CrO}$ in an aqueous solution under annular type photo-reaction with direct sunlight.

\section{Photo-degradation of the Organic Dyes under Solar Irradiation}

Experiments were carried out under the sun light. To $50 \mathrm{ml}$ of dye solution (10 mg l1), $10 \mathrm{mg}$ of catalyst [31-33] was added and suspension was subjected to solar light irradiation. The aqueous suspension was magnetically stirred throughout the experiment. For a given time interval, a small quantity of the mixture solution was pipetted into a quartz cell, and its absorption spectrum was measured using an UV-Vis spectrophotometer

\section{Result and discussion}

\section{$5.1 \mathrm{pH}$ and TDS measurement}

This work carried out the some preliminary analysis of the nanoparticle synthesis, such as $\mathrm{pH}$ ananlysis, because $\mathrm{pH}$ is the main factor to form nanoparticles, $\mathrm{pH}$ is measured by digital $\mathrm{pH}$ meter, OBL extract and $0.1 \mathrm{M}$ potassium dichromate solution also shown in acidic, after the nanoparticle synthesis obtained nanoparticle suspension increase the acidity, at same time TDS analysis were ./carried out to shown in the nanoparticle suspension, increases the total dissolved suspension(TDS) value, it is revealed that the nucleation[34] of phytoconstituent in chromium metal cations.

\subsection{Ultraviolet spectroscopy (UV)}

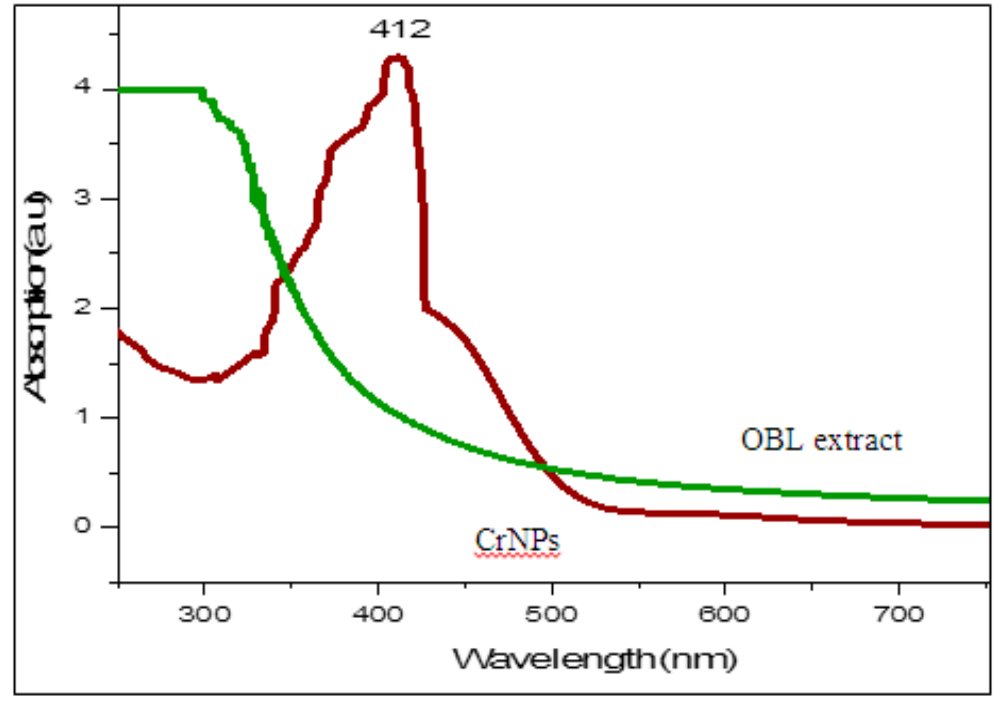

Figure:3 UV-Vis spectrum of $\mathrm{CrO}_{3} \mathrm{NPs}$ nanoparticles

UV-vis absorption spectra were recorded for $\mathrm{Cr}_{2} \mathrm{O}_{3} \mathrm{NPs}$ in the range of 200-800 nm using an aqueous $\mathrm{Cr}_{2} \mathrm{O}_{3}$ NPs suspension. The samples displayed an optical absorption peaks of absorption maximum value have been shown $412 \mathrm{~nm}$ for all the nanoparticle suspension but concentrations increases absorption $(\mathrm{a}, \mathrm{u})$ only increases. The increasing shift of the UVvis peak of $\mathrm{Cr}_{2} \mathrm{O}_{3} \mathrm{NPs}$ may be due to the aggregation of the nanoparticles as a Chromuim oxide nano-assemblage. The dynamic absorption peaks are shown at $412 \mathrm{~nm}$ is evidence of the existence of various organic compounds that interact with Chromium oxide ions in 
solution and implies a possible course for the reduction of the metal ions present in the solution the merged UV spectrum had been shown in Figure:3.

\subsection{FT-IR analysis}

The FTIR analysis was further performed to determine the phyto-constituent containing functional groups involved in synthesizing $\mathrm{Cr}_{2} \mathrm{O}_{3}$ nanoparticles as reducing and capping agents. Figure 4 a,b,c presented the FTIR spectrum of plant leaf extract and nanoparticles. The results of OBL leave extract FTIR spectrum (Figure:4a) demonstrated that the frequency of $3118 \mathrm{~cm}^{-1}$ at the very broad peak (range $4000-2000 \mathrm{~cm}^{-1}$ )represent the various stretching frequencies are merged to appeared it, this peak had been screened out -O$\mathrm{H}$ group in alcohols and acids , $-\mathrm{N}-\mathrm{H}$ group in amide, $-\mathrm{C}=\mathrm{N}$ nitrile, $-\mathrm{C}-\mathrm{H}$ aromatic stretching and aldehydic $-\mathrm{CH}$ stretching frequencies, frequency of $1597 \mathrm{~cm}^{-1}$ is represent in $\mathrm{N}-\mathrm{H}$ bending), weak peak of $1384 \mathrm{~cm}^{-1}-\mathrm{C}-\mathrm{H}$ bending in gem dimethyl, $-\mathrm{OH}$ bending vibration have shown in the frequency $1333 \mathrm{~cm}^{-1}$, medium sharp peak of $1283 \mathrm{~cm}^{-1}$ is $-\mathrm{C}-\mathrm{O}$ aromatic ester, the frequency of $1193 \mathrm{~cm}^{-1}$ has demonstrate $-\mathrm{C}-\mathrm{O}$ stretching in tertiary alcoholic group , the secondary alcoholic group represent in $1095 \mathrm{~cm}^{-1}$ frequency, primary alcoholic stretching has shown in the $1048 \mathrm{~cm}^{-1}, \mathrm{C}=\mathrm{C}$ bending di-substituted alkene represented in $970 \mathrm{~cm}^{-1}, \mathrm{C}-\mathrm{H}$ bending in out of plane in aromatic di substituted benzene has shown in $817 \mathrm{~cm}^{-1}$, benzene derivatives are shown in $712 \mathrm{~cm}^{-1}$, -C-X of halide bond in 643 and $602 \mathrm{~cm}^{-1}$, the frequency $535 \mathrm{~cm}^{-1}$ have shown in the $-\mathrm{C}-\mathrm{H}$ in plane in aliphatic carbon chain. The synthesized nanoparticles displayed different FTIR peaks at Figure 4b; corresponding to alcoholic O-H ( $\operatorname{sharp} 3401 \mathrm{~cm}^{-1}$ ) this sharp peak represented the chromium metal ions reduced many acid and aldehydic groups to alcoholic group, amidic $\mathrm{C}=\mathrm{O}$ shown in $1631 \mathrm{~cm}^{-1}, \mathrm{C}-\mathrm{H}$ bending vibration methyl group in1404 $\mathrm{cm}^{-1}$, Hydrate peaks represented in $1159 \mathrm{~cm}^{-1}$, strong $-\mathrm{C}-\mathrm{H}$ bending vibration in 1,4 di substituted aromatic groups in $813 \mathrm{~cm}^{-1}$, the frequency of $594 \mathrm{~cm}^{-1}$ have shown in $\mathrm{Cr}-\mathrm{O}$ stretching vibrations[35-39]. These peaks are matched with the FTIR signals of the OBL leaves extracts with chromium nano particle are slight shifting (Figure:4c). These results suggest that many biologically active phyto-molecules are left adsorbed on the surface of the $\mathrm{Cr}_{2} \mathrm{O}_{3}$ nanoparticle.

\subsection{XRD analysis}

The crystalline form of the green synthesized $\mathrm{Cr}_{2} \mathrm{O}_{3}$ nanoparticles was indomitable by XRD scrutiny, and the results are presented in Figure 5. The XRD spectrum of synthesized nanoparticles revealed nine different Bragg's diffraction peaks, indexing to crystal planes of (012), (104), (110), (113), (024), (116), and (306) at $2 \theta=24.5^{\circ}, 33.6^{\circ}, 36.2^{\circ}, 41.5^{\circ}, 50.2^{\circ}$, $54.9^{\circ}$, and $79.1^{\circ}$, respectively. The diffraction peaks of $\mathrm{Cr} 2 \mathrm{O} 3$ nanoparticles are wellmatched with Joint Committee on Powder Diffraction Standards (JCPDS) 38-1479 [40, 41]. The associated with impurities were not observed, indicating the purity of the nanoparticles. The peak's intensity further displayed the high crystalline nature of the nanoparticles. 


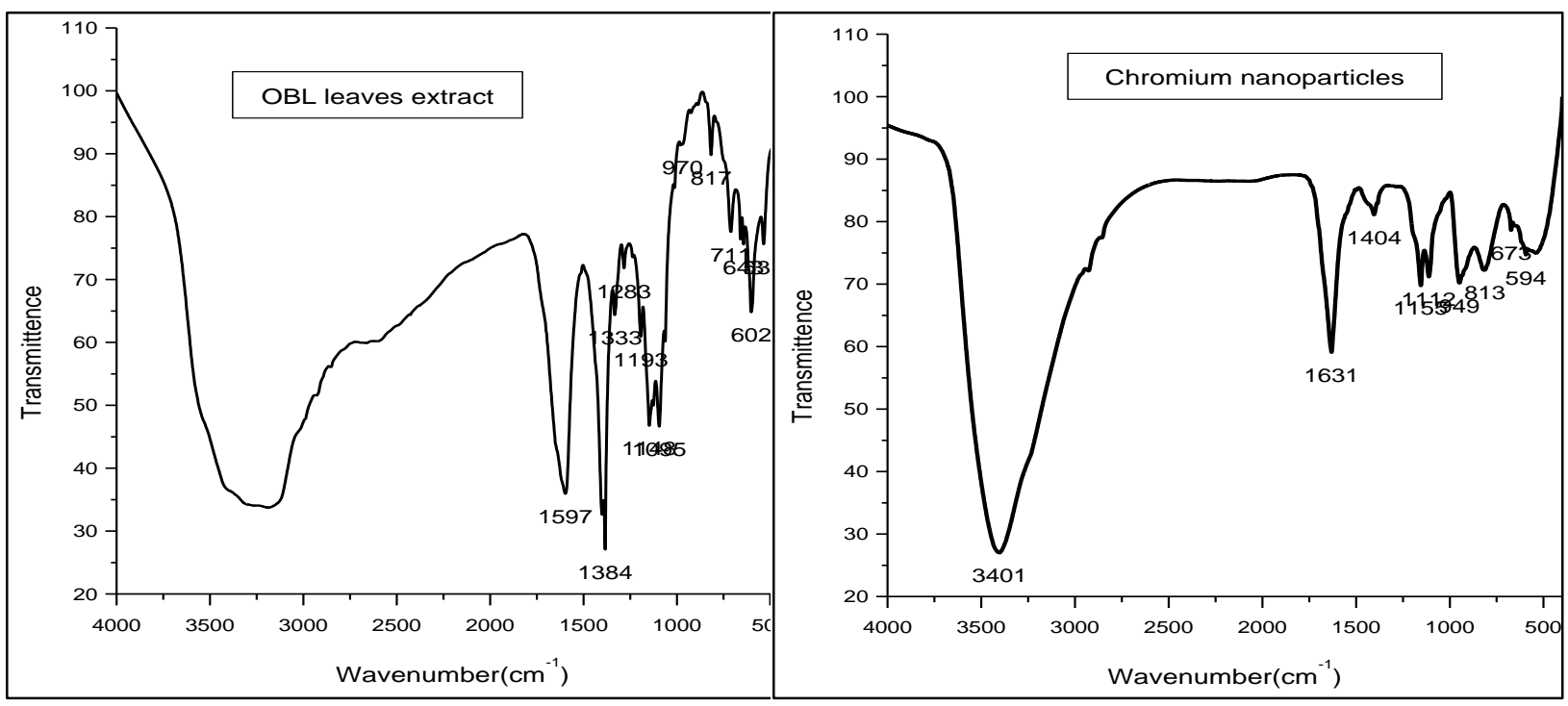

Fig:4 a FTIR spectrum of OBL leave extract

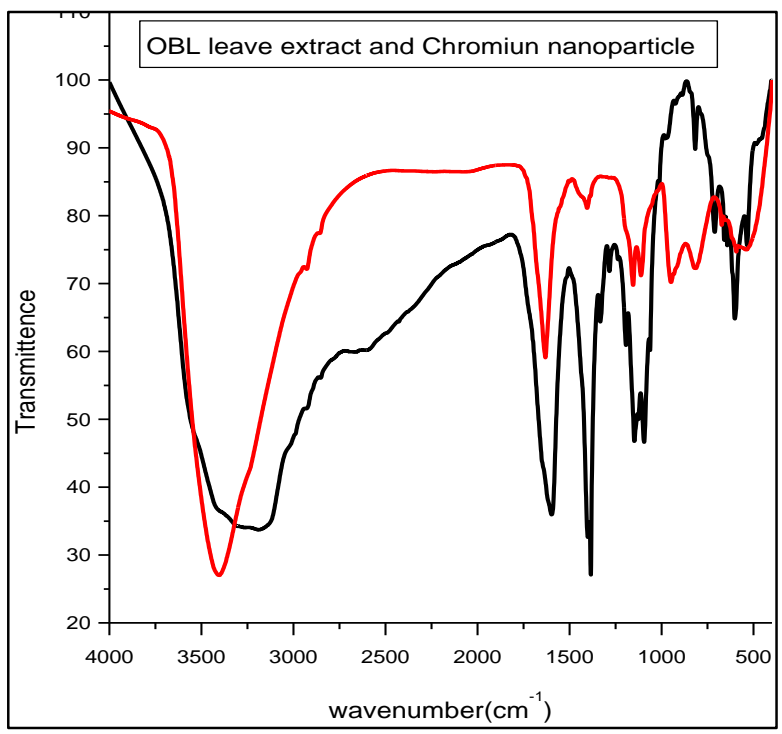

Fig 4c: compained spectrum of $4 \mathrm{a} \& 4 \mathrm{~b}$
Fig:4 b FTIR spectrum of CrNPs

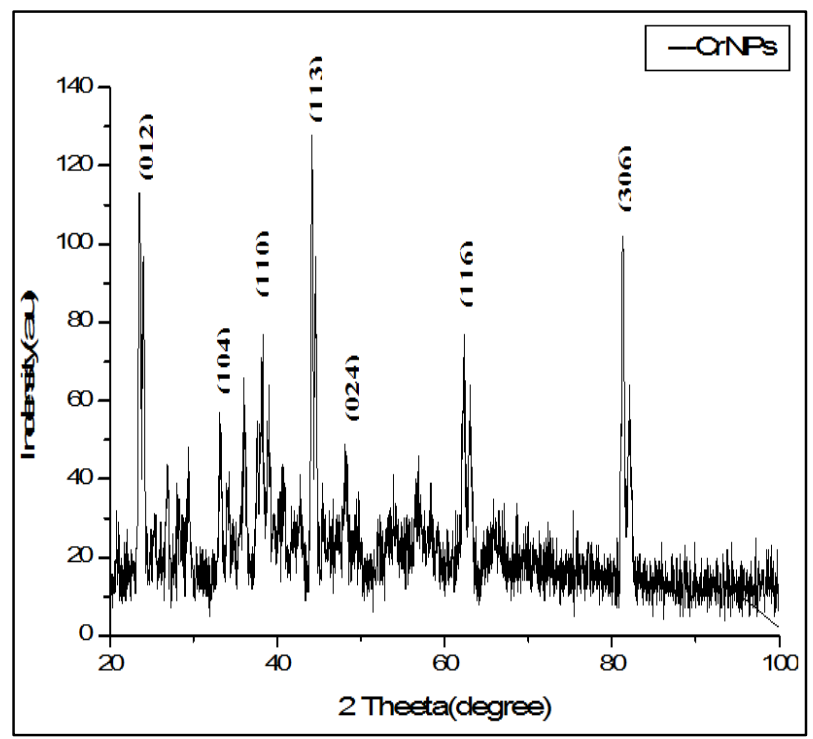

\subsection{DLS analysis}

Fig:5 XRD image of Chromium nanoparticles

DLS is often interpreted to as a scattering of quasi-elastic light. It fulfills the role of size distribution and agglomeration of selective NPs [42-43]. This process is quite sensitive, rapid and it can calculate the mean size of a particle on both macro and nano scale. The speed of the DLS technique is based on particle size. Small particles in suspension undergo random thermal motion known as Brownian motion. This random motion is modeled by the Stokes-Einstein equation. Below the equation is given in the form most often used for particle size analysis. The DLS analysis of green synthesized chromium nanoparticle to shown the average size of the nanoparticle is $42.35 \mathrm{~nm}$. This result also shown in some of the nanoparticle having more than $100 \mathrm{~nm}$, this is due to growth of the nanoparticle and aggregation of the two is more nanoparticles.

$$
\mathrm{D}_{\mathrm{h}}=\frac{K_{B} T}{3 \pi \eta D_{t}}
$$


$\mathrm{Dh}=$ The hydrodynamic diameter (this is the goal: particle size!)

$\mathrm{Dt}=$ The translational diffusion coefficient (we find this by dynamic light scattering)

$\mathrm{kB}=$ Boltzmann's constant (we know this)

$\mathrm{T}=$ thermodynamic temperature (we control this)

$\eta=$ dynamic viscosity (we know this)

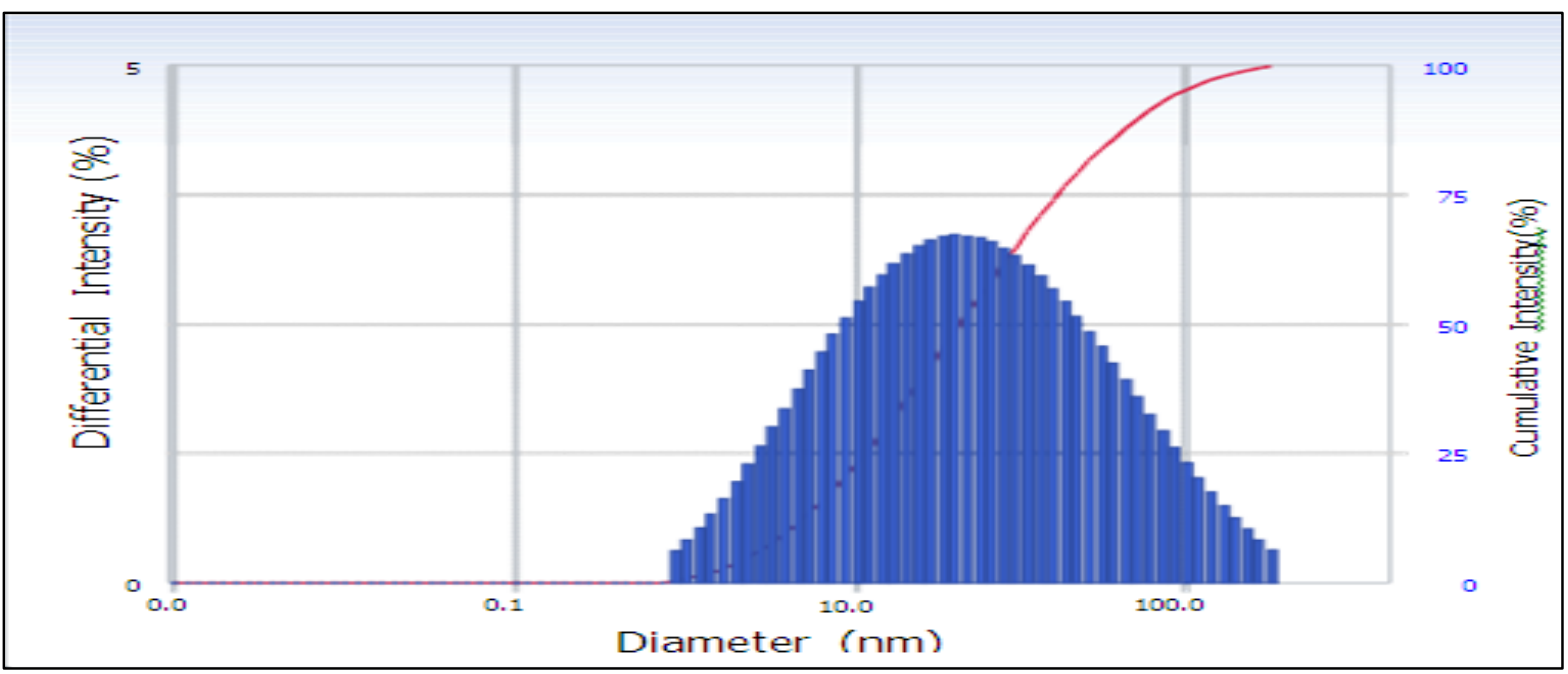

Figure:6 DLS result analysis of Cr2O3 nanoparticle by OBL extract

\subsection{SEM and EDS analysis}

The morphology determined by SEM analysis of green synthesized $\mathrm{Cr}_{2} \mathrm{O}_{3}$ nanoparticle by OBL extract have shown, Figure 7(a, b, c). It can be seen from SEM image that $\mathrm{Cr}_{2} \mathrm{O}_{3} \mathrm{NPs}$ are agglomerated and not well formed. One can vividly see well defined nanoparticles with distinguish shapes. Specifically, SEM image for $\mathrm{Cr}_{2} \mathrm{O}_{3} \mathrm{NPs}$ reveal distinguishable rhomboid shaped nanoparticles, elongated nanorods and highly agglomerated nanoparticles., $\mathrm{Cr} 2 \mathrm{O} 3$ nanoparticles become well-formed reveling distinct shapes. To identify chemical elements and purity of synthesised samples Figure 7a shown in $10 \mu \mathrm{m}$, Figure $7 \mathrm{~b} \&$ $\mathrm{c}$ has been shown $1 \mu \mathrm{m}$, EDS analysis were performed and results are shown in Figure. 8a. and $8 \mathrm{~b}$, According to EDS spectra, the most pronounced and only chemical elements presents on samples are $\mathrm{O}$ and $\mathrm{Cr}$. Cleary, there are no other chemical elements identified in the sample which confirm purity of synthesised sample as $\mathrm{Cr}_{2} \mathrm{O}_{3}$ nanoparticles. The size of the nanoparticle have shown in EDS image is $10 \mu \mathrm{m}$, Table 1 gives the atomic percentages of chemical elements on samples. As one can see in this table, there are differences in the atomic percentages of the chemical elements in the different shape of nanoparticles 

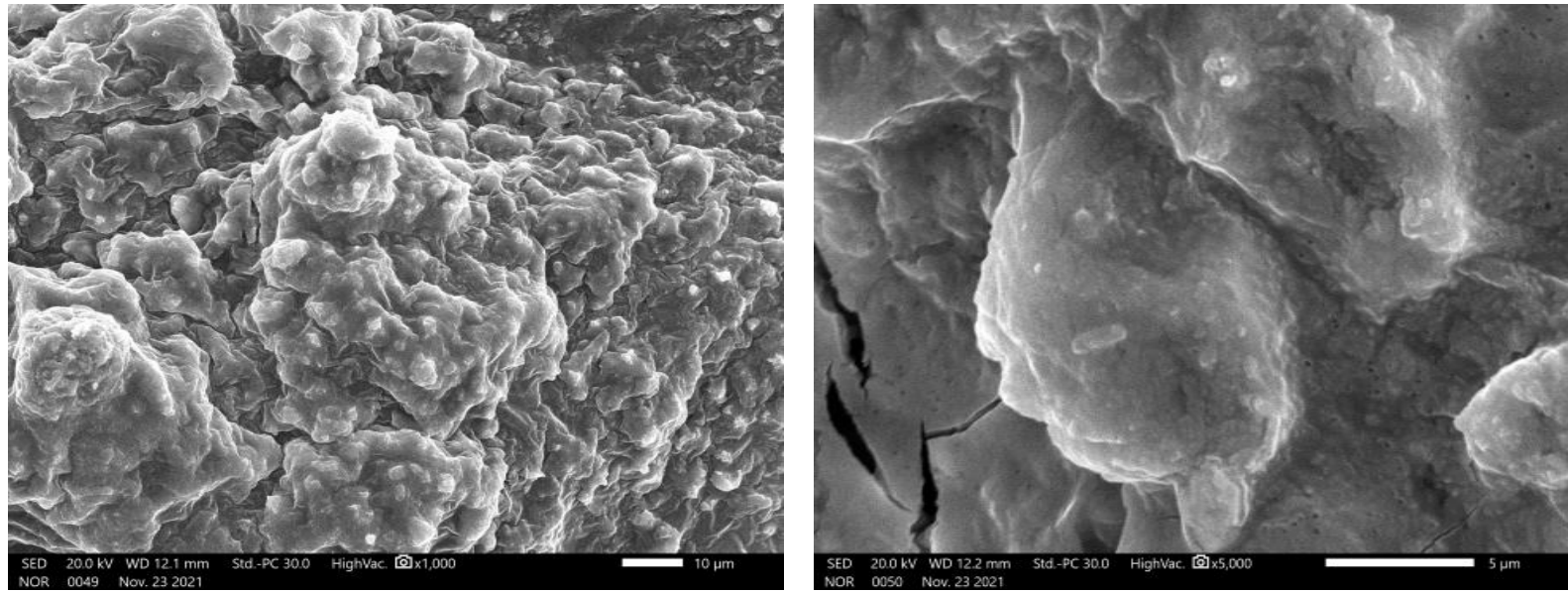

Figure:7a SEM image of $\mathrm{Cr}_{2} \mathrm{O}_{3} \mathrm{NPs}$

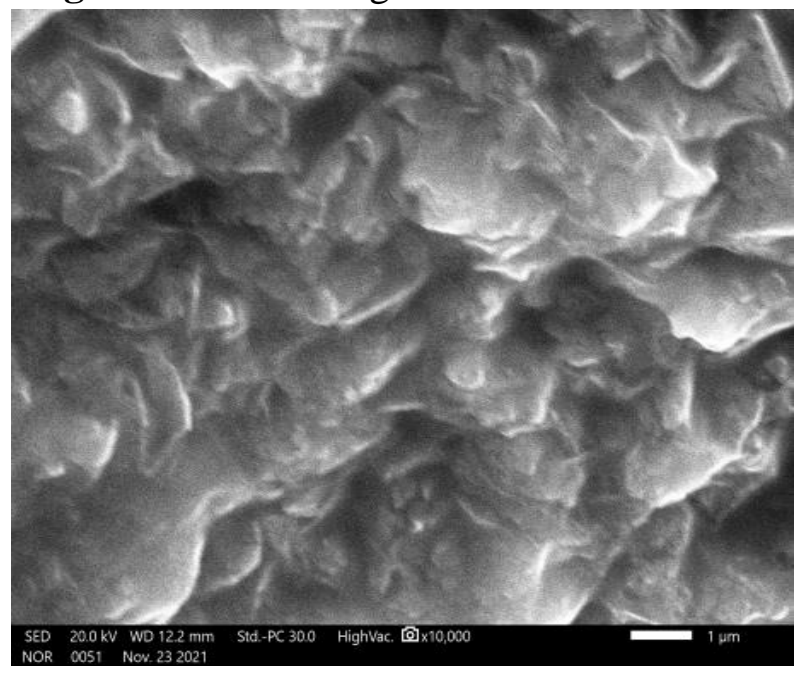

Figure:7c SEM image of $\mathrm{Cr}_{2} \mathrm{O}_{3} \mathrm{NPs}$

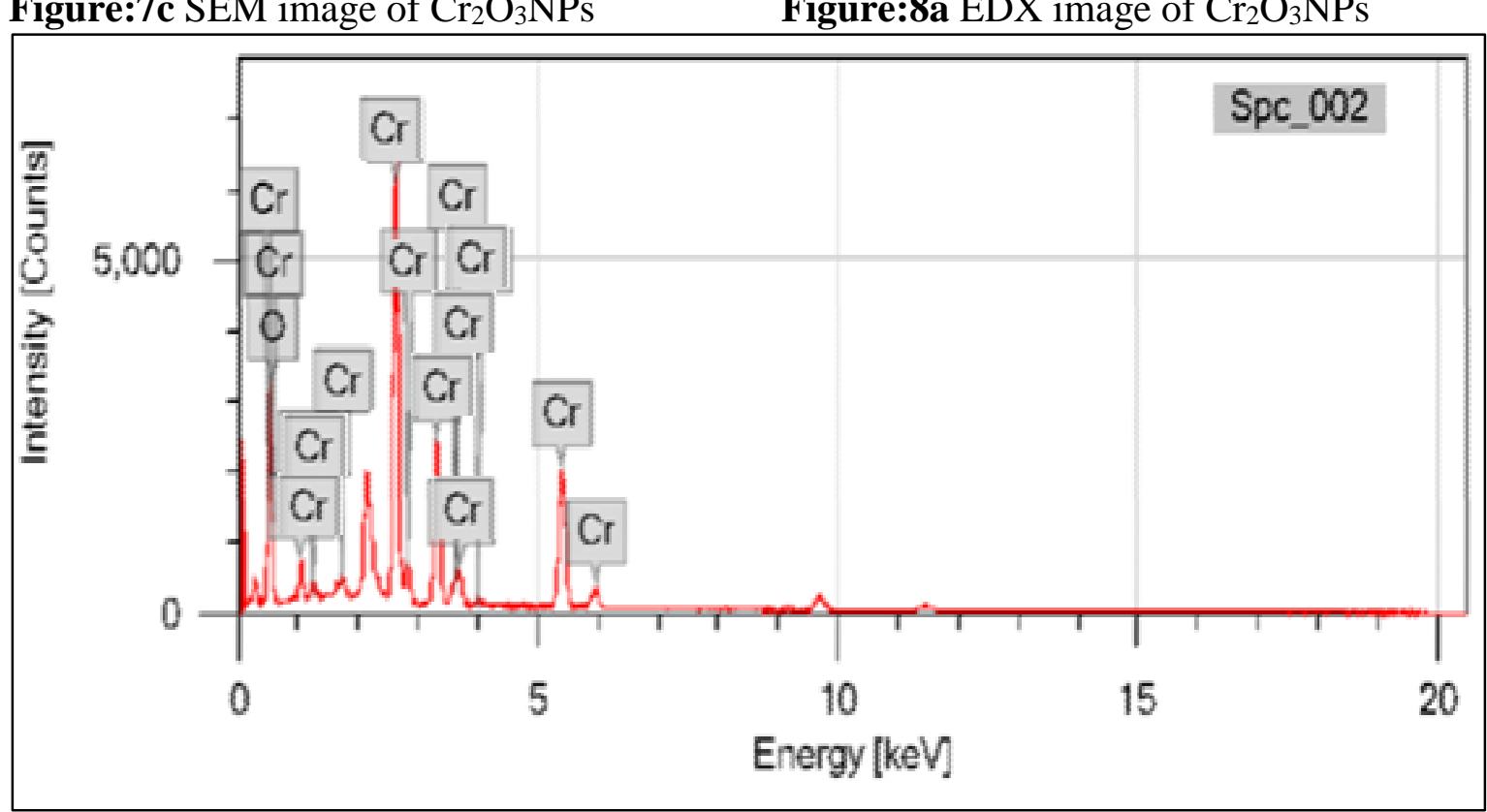

Figure:8b EDX Spectrum of $\mathrm{Cr}_{2} \mathrm{O}_{3} \mathrm{NPs}$

Figure:7b SEM image of $\mathrm{Cr}_{2} \mathrm{O}_{3} \mathrm{NPs}$

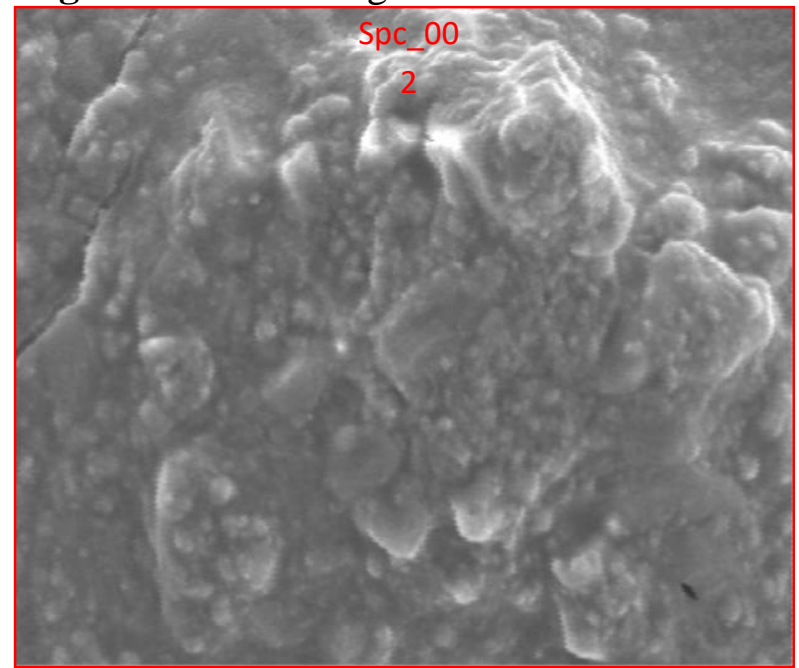

Figure:8a EDX image of $\mathrm{Cr}_{2} \mathrm{O}_{3} \mathrm{NPs}$ 
Table:1 EDS values of $\mathrm{Cr}_{2} \mathrm{O}_{3} \mathrm{NPs}$ by $\mathrm{OBL}$ leaves extract

\begin{tabular}{|c|c|r|rr|}
\hline Element & Line & Mass\% & \multicolumn{2}{|c|}{ Atom\% } \\
\hline $\mathrm{O}$ & $\mathrm{K}$ & $29.31 \pm 0.25$ & $50.38 \pm 0.44$ \\
\hline $\mathrm{Cr}$ & $\mathrm{K}$ & $70.69 \pm 0.75$ & $49.63 \pm 0.66$ \\
\hline Total & & 100.00 & 100.00 \\
\hline Spc_002 & & & Fitting ratio 0.1627 \\
\hline
\end{tabular}

\subsection{TEM analysis}
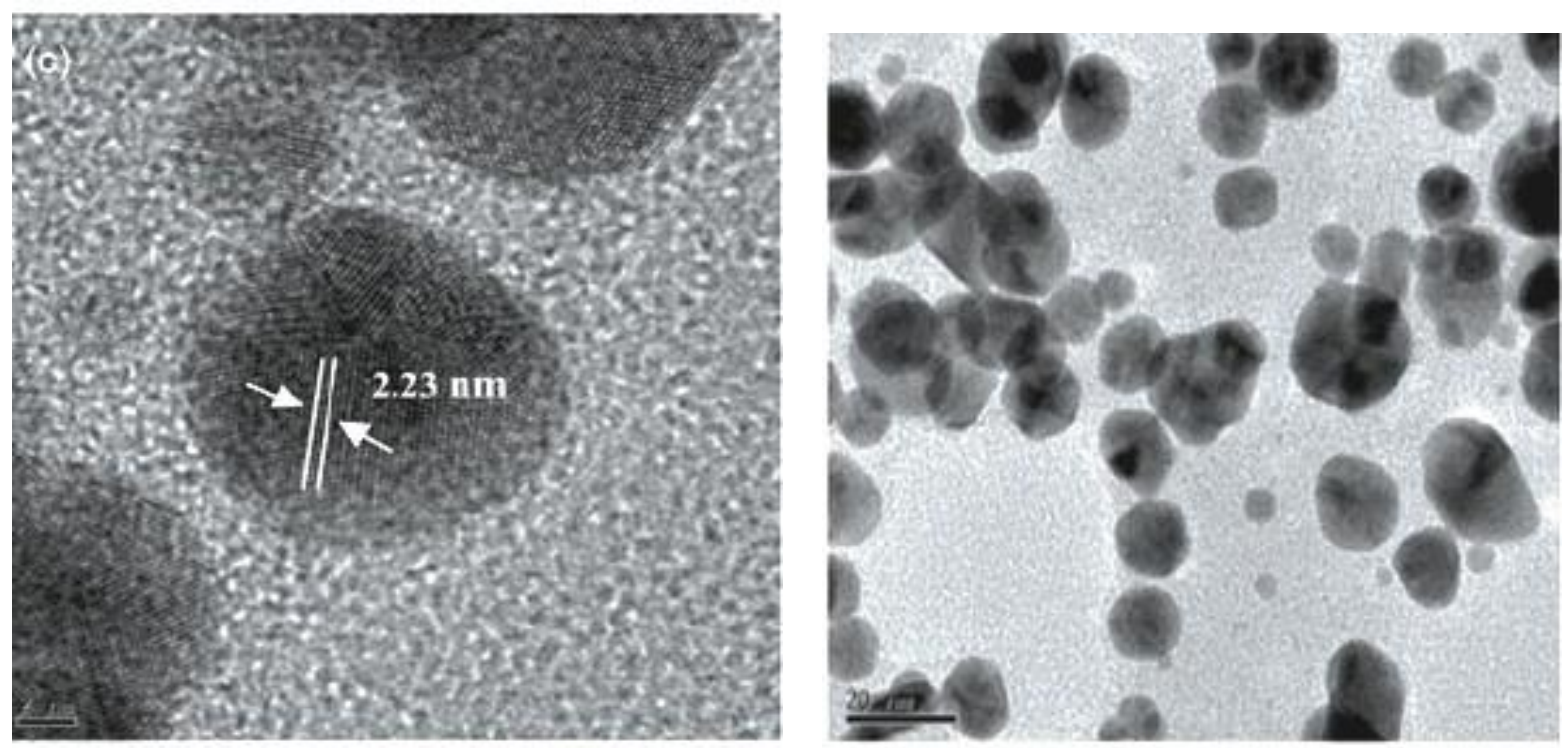

Figure:9 TEM images of $\mathrm{Cr}_{2} \mathrm{O}_{3} \mathrm{NPs}$

Most of the $\mathrm{Cr}(\mathrm{III})$ nanoparticles were circular in shape [44] and evenly distributed without any aggregation. The size of the particles varied from 4 to $70 \mathrm{~nm}$, with a mean size of about $55.9 \pm 13.3 \mathrm{~nm}$.

\section{Photo-degradation of Organic dyes}

The industrialization of the modern world to develop the massive textile industries, these industries intense apprehensions were engrossed on the contamination of the environment caused by dye pollutants, which caused severe environmental pollution and health problems due to the variety, toxicity and persistence characteristics [45-50]. Most of dyes are characterized by complicated constitution and high chemical stability, hence persist for long distances in flowing water, retards photosynthetic activity, inhibit the growth of aquatic biota by blocking out sunlight and utilizing dissolved oxygen and also decrease the recreation value of stream [51]. Therefore degradation of the dyes in industrial wastewaters has generated considerable attention due to their huge volume of production, slow biodegradation, low decoloration and high toxicity [52-55]. Metal oxides can adopt a vast number of structural geometries with an electronic structure that can exhibit metallic, semiconductor or insulator character and therefore play a very important role in many areas of chemistry, physics and materials science [56-60]. In recent years, an enormous interest has been devoted to heterogeneous photo catalysis using metal oxides 


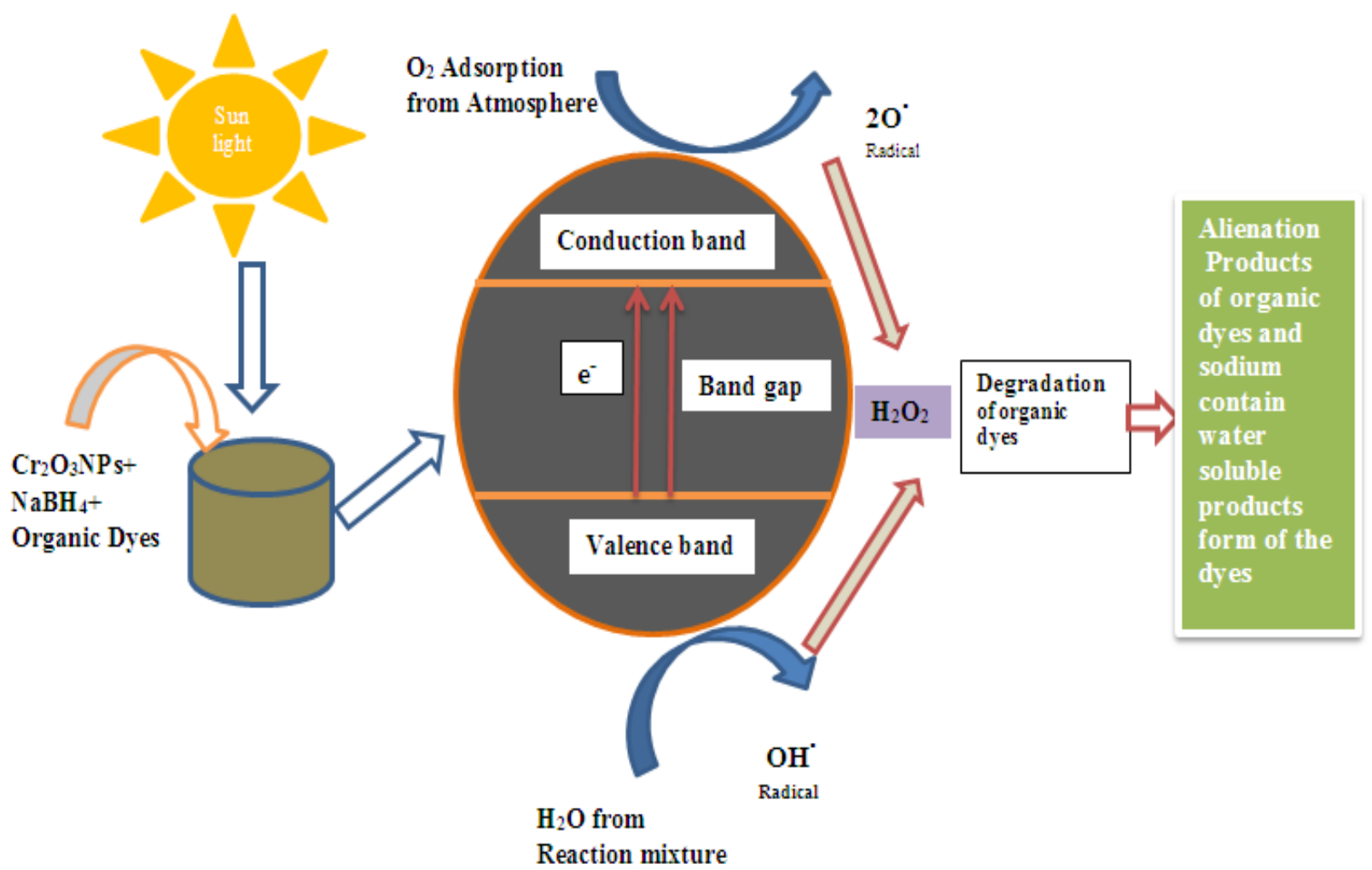

Figure:10 Mechanisam of photo degradation of organic dyes with $\mathrm{Cr}_{2} \mathrm{O}_{3} \mathrm{NPs}$

Owing to its potential applications to both environmental applications and organic synthesis [61-65]. Many attempts have been made to study photo catalytic activity of four different dyes such as Methyl orange (MO), Methyl red (MR), Methyl blue (MB) and Alizarin red (AR). Sunlight is abundantly available natural source of energy which can be conveniently exploited for the irradiation of semiconductors in the photo-degradation of pollutants and can make the process economically more viable $[66,67]$. Dyes can be degraded in the presence of photo-catalyst upon irradiation with visible light because of their absorption in the visible region. Outstanding to their complex aromatic structures, organic pollutants/dyes are very stable in aqueous solutions, which is a big concern for environmental water pollution. To remove organic pollutants, a tentative reaction mechanism is proposed, which involves $\mathrm{OH}$ free radicals as active oxidizing agents during the photo-catalytic process. During light-driven catalytic degradation, the band position of the catalyst determines the strength of the oxidation or reduction process. The catalyst nanomaterials are excited by light irradiation and form electron-positive hole pairs $\left(\mathrm{e}^{-} / \mathrm{h}^{+}\right)$pairs called exactions) which interact with hydride radicals (of the $\mathrm{NaBH}_{4}$ reducing agent) to create a reactive oxygen species known as a superoxide $(\mathrm{O} 2-)$ ion and hydroxyl free radicals. [68] The oxygen-containing radicals $\left(\mathrm{O}_{2}-\right.$ • and $\mathrm{HO} \bullet$ ) might react with electrons and holes to produce more hydroxyl radicals $(\bullet \mathrm{OH})$, which derive photo-degradation efficiency and enable ultrafast degradation of the organic dye under UV-vis light irradiation. The degradation of azo dyes in the process produces amine derivatives (colorless) which finally decompose to produce $\mathrm{CO}_{2}$ and water. To evaluate the effect of dye adsorption on the catalyst surface, the $\mathrm{Cr}_{2} \mathrm{O}_{3} \mathrm{NPs}$ catalyst was dissolved in the organic dyes in aqueous solution and stirred for $12 \mathrm{~h}$ at room temperature. When a freshly prepared aqueous solution of $\mathrm{NaBH}_{4}$ was added to 
Table:2 Organic dyes and chemical properties

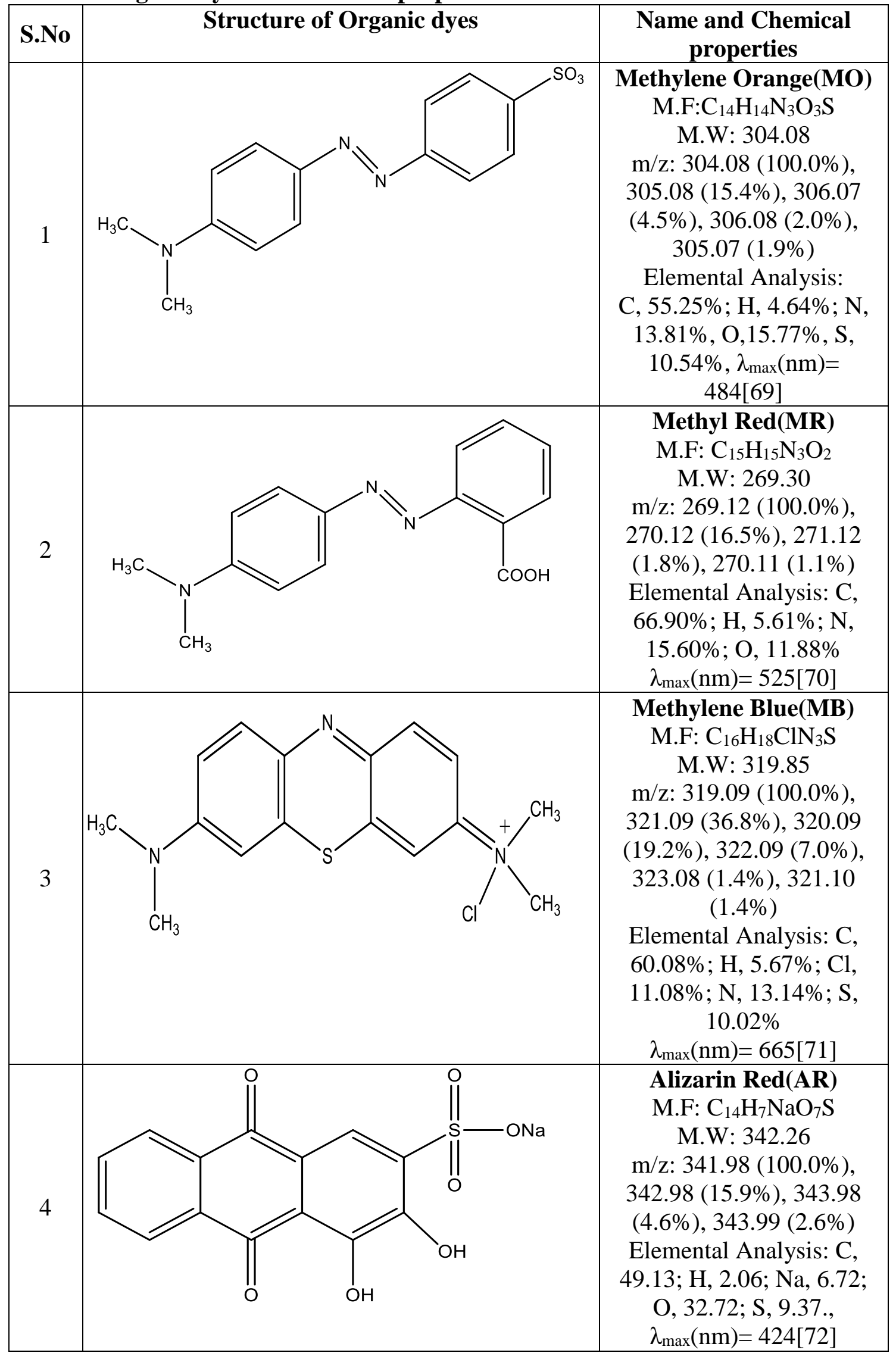


6.1 Proposed Mechanism of Photo-Degradation of the Organic dyes/Dye Solutions.

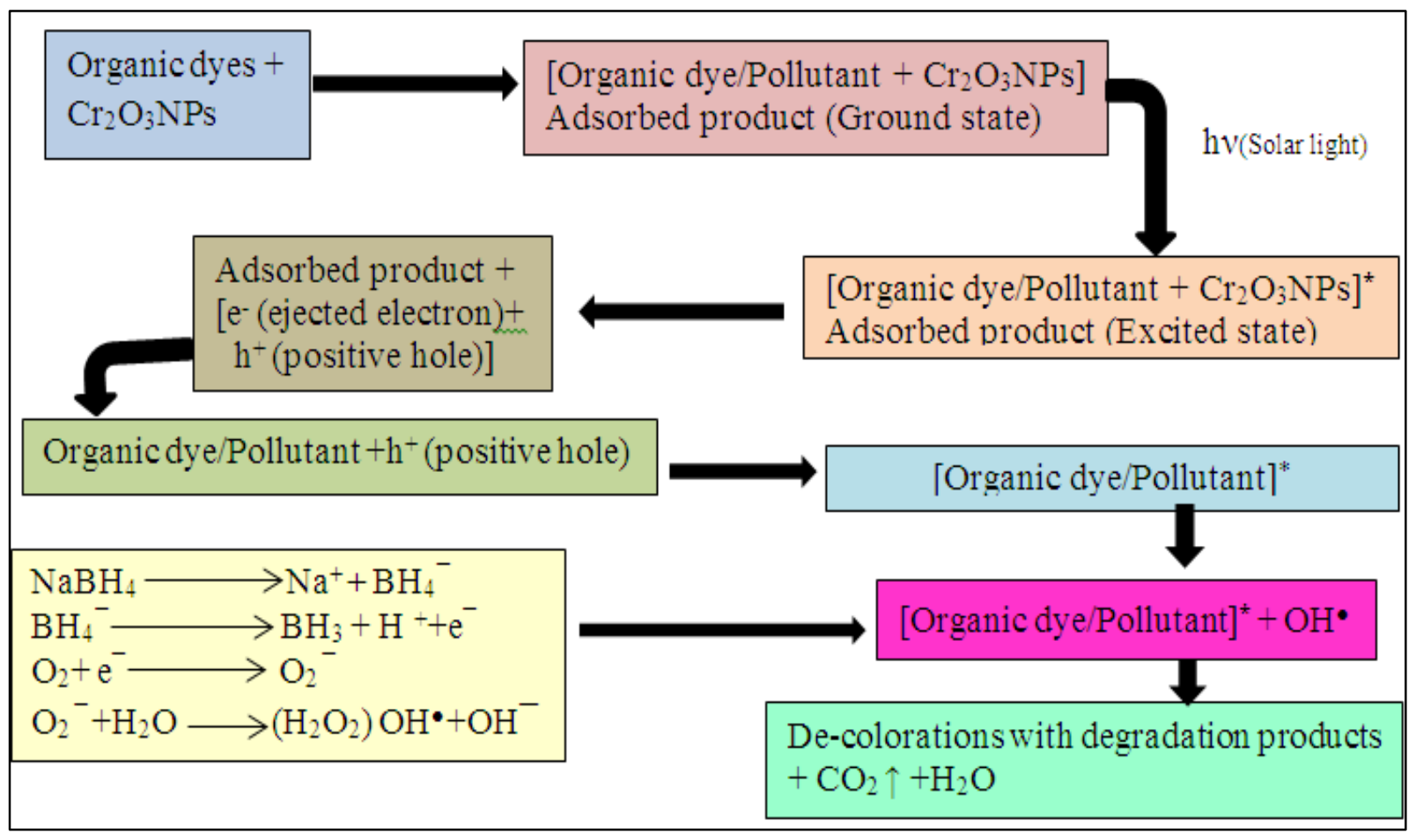

The organic dyes solution in the absence of the NPs catalyst, no visible color change could be observed. Nevertheless, maximum absorption peak centered at organic dyes wavelength (nm) remained unaltered even after excessive addition of the $\mathrm{NaBH}_{4}$ solution, which proved no degradation of the organic dyes in the absence of the catalyst. At the chemical structural point, the presence of various functional groups in the organic dyes can significantly affect photo-degradation performance and yield of reaction. The chromophore groups and azo bonds in dyes are responsible for the color and display a strong peak at a wavelength due to $\mathrm{n}$ $\rightarrow \pi^{*}$ transition which is susceptible to photo catalytic degradation under UV light. At $t=0$ min, UV absorption spectra of the organic dyes solution with and without the NPs catalyst were recorded at room temperature. The degradation started with the addition of the $\mathrm{NaBH}_{4}$ solution in terms of intensity decrease at room temperature. Hence, organic dyes degradation might follow a possible breakage of the azo bond as the chromophoric group, which causes decolorization of the dye solution via the following steps during organic dye degradation, the $\mathrm{Cr}_{2} \mathrm{O}_{3} \mathrm{NPs}$ displayed efficient catalytic activity with $\mathrm{NaBH}_{4}$ as the reducing agent in aqueous solution. The process was monitored by UV-vis spectrophotometry at room temperature. The sodium borohydride $\left(\mathrm{NaBH}_{4}\right)$ reducing agent [73-74] acts as a hydride ion source (to produce electrons), while $\mathrm{Cr}_{2} \mathrm{O}_{3} \mathrm{NPs}$ catalysts activate the azo bond of the organic dye via conjugation. Additionally, ultrafast dye degradation with $\mathrm{Cr}_{2} \mathrm{O}_{3} \mathrm{NPs}$ might be due to additional electrons generated by $\mathrm{BH}_{4}-$ and efficient charge transfer by the $\mathrm{Cr}_{2} \mathrm{O}_{3} \mathrm{NPs}$ catalyst toward the organic dye. Dye solution with catalyst was stirred in dark for 20min to establish adsorption desorption equilibrium on the catalyst surface. The reaction mixture was exposed to sun light. At certain regular time intervals, aliquots of samples were collected through $0.45 \mu \mathrm{m}$ Millipore syringe filter. The filtrate was subjected to UV spectrometer at a wave length of $484 \mathrm{~nm}$ of methyl orange, $525 \mathrm{~nm}$ for methyl red, $665 \mathrm{~nm}$ in methyl blue and $424 \mathrm{~nm}$ in alizarin red dyes. To have a comprehensive comparison, the reaction environment is maintained the same for all the activity tests.

The percentage degradation of dye was calculated from the following equation: 


$$
\% \text { of Degradation }=\frac{A o-A t}{A o} \times 100
$$

Where $A o$ is initial absorbance of dye solution before degradation and At is absorbance of dye solution at time $t$.

\subsubsection{Photo degradation of Methyl orange (MO)}

The degradation of $\mathrm{MO}$ dye was performed at room temperature using unsupported nanoparticles at an unmodified $\mathrm{MO}$ dye $\mathrm{pH}$ of $\sim 4.5$; this was also performed to optimize the degradation of $\mathrm{MO}$ using $\mathrm{Cr}_{2} \mathrm{O}_{3} \mathrm{NPs}$. It was observed that the color of the MO dye fades away as the degradation [75-79] occurs within just a few minutes of stirring the MO solution in the presence of nanoparticles. The UV absorption spectra of the MO dye solution showed a gradual decrease in the height of the absorption band for MO at the wavelength of $464 \mathrm{~nm}$ over time; displaying the decline in MO dye concentration in the solution. In Figure 11a and $11 \mathrm{~b}$, it is observed that $\mathrm{MO}$ dye degradation by the nanoparticles occurs rapidly.

\subsubsection{Photo degradation of Methyl red (MR)}

The degradation of MR dye [80-82] was performed at room temperature using unsupported nanoparticles at an unmodified MR dye $\mathrm{pH}$ of $\sim 4.4-6.2$; this was also performed to optimize the degradation of MR using $\mathrm{Cr}_{2} \mathrm{O}_{3} \mathrm{NPs}$. It was observed that the color of the MR dye fades away as the degradation [83-89] occurs within just a few minutes of stirring the MR solution in the presence of nanoparticles. The UV absorption spectra of the MR dye solution showed a gradual decrease in the height of the absorption band for MR at the wavelength of $525 \mathrm{~nm}$ over time; displaying the decline in MR dye concentration in the solution. In Figure 11c and 11d, it is observed that MR dye degradation by the nanoparticles occurs rapidly.

\subsubsection{Photo degradation of Methyl blue (MB)}

The degradation of MB dye [90-94] was performed at room temperature using unsupported nanoparticles at an unmodified $\mathrm{MB}$ dye $\mathrm{pH}$ of $\sim 6$; this was also performed to optimize the degradation of MR using $\mathrm{Cr}_{2} \mathrm{O}_{3} \mathrm{NPs}$. It was observed that the color of the MR dye fades away as the degradation [95-100] occurs within just a few minutes of stirring the MR solution in the presence of nanoparticles. The UV absorption spectra of the MR dye solution showed a gradual decrease in the height of the absorption band for MB at the wavelength of $665 \mathrm{~nm}$ over time; displaying the decline in MR dye concentration in the solution. In Figure 11e and 11f, it is observed that MR dye degradation by the nanoparticles occurs rapidly.

\subsubsection{Photo degradation of Alizarin red (AR)}

The degradation of AR dye [101-102] was performed at room temperature using unsupported nanoparticles at an unmodified $\mathrm{AR}$ dye $\mathrm{pH}$ of $\sim 4.3$; this was also performed to optimize the degradation of AR using $\mathrm{Cr}_{2} \mathrm{O}_{3}$ NPs. It was observed that the color of the AR dye fades away as the degradation [103-104] occurs within just a few minutes of stirring the MR solution in the presence of nanoparticles. The UV absorption spectra of the AR dye solution showed a gradual decrease in the height of the absorption band for MB at the wavelength of $424 \mathrm{~nm}$ over time; displaying the decline in MR dye concentration in the solution. In Figure $11 \mathrm{~g}$ and $11 \mathrm{~h}$, it is observed that AR dye degradation by the nanoparticles occurs rapidly. 


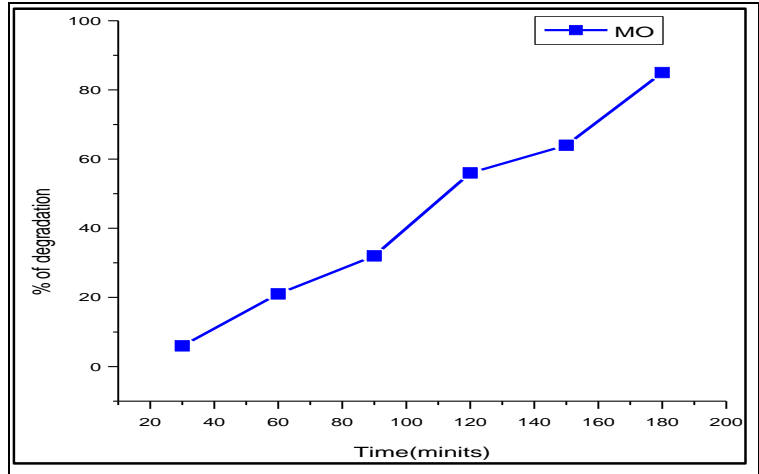

Figure:11a

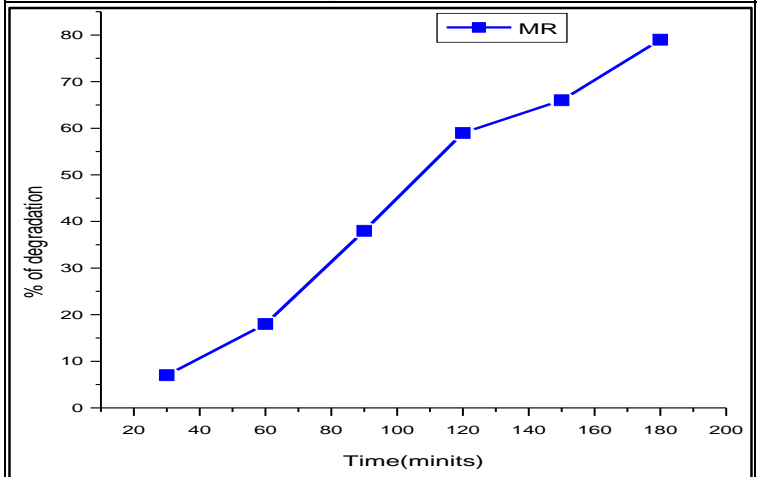

Figure:11c

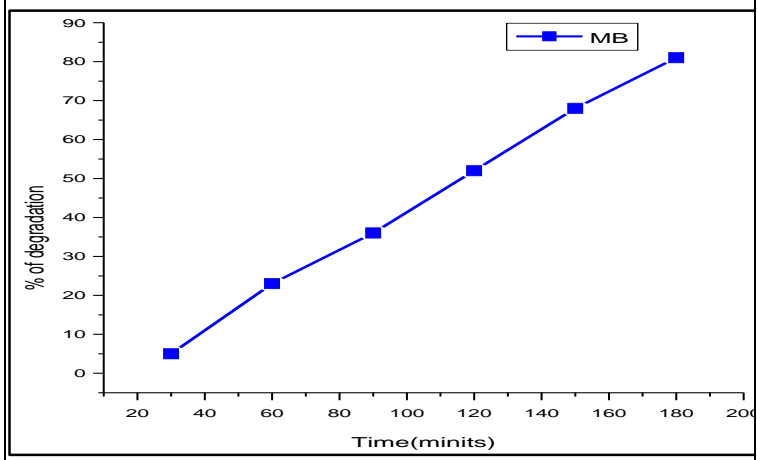

Figure:11e

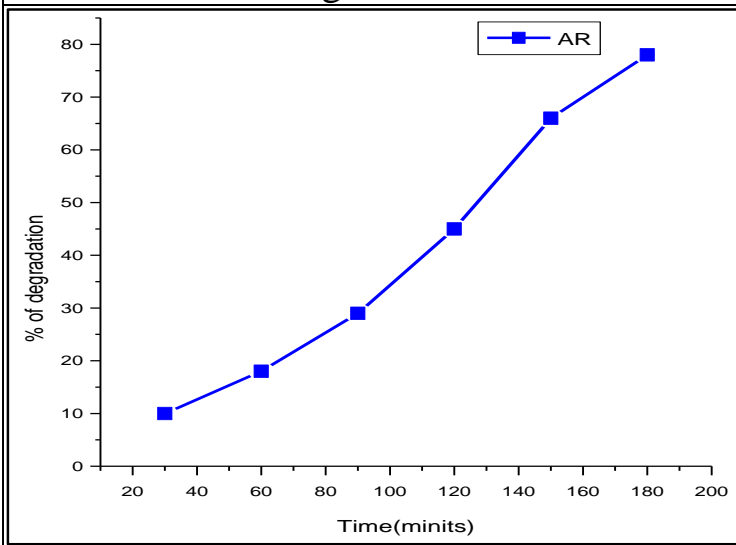

Figure: $11 \mathrm{~g}$

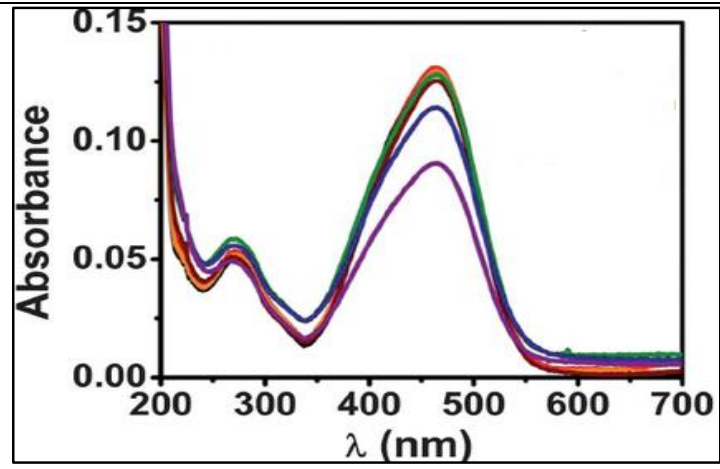

Figure:11b

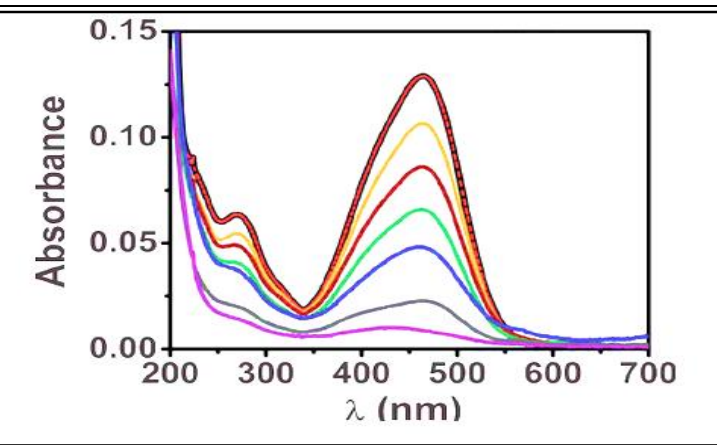

Figure:11d

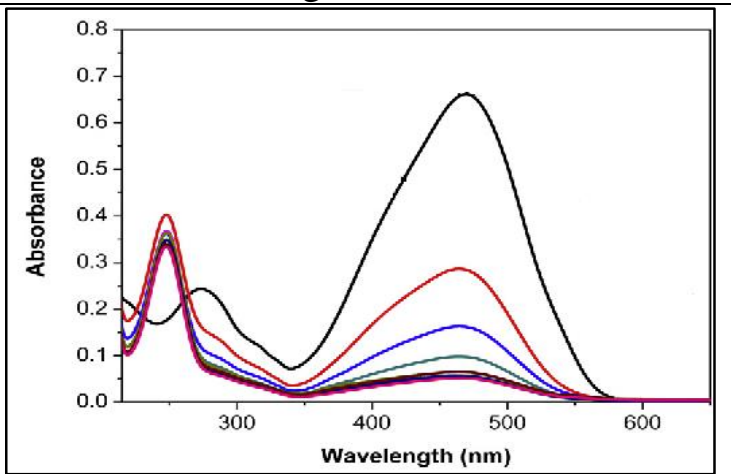

Figure:11f

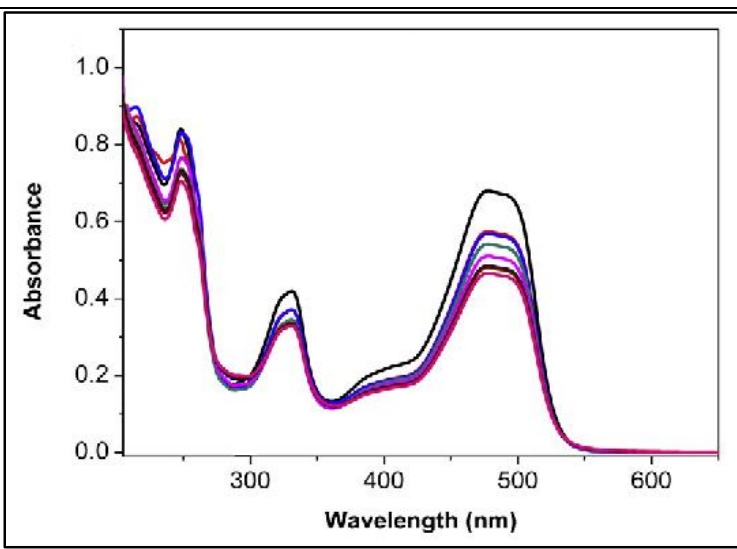

Figure:11h

Figure: 11 a,c,e,g: shown in \% of degradation of organic dyes MO,MR,MB and AR

Figure: 11 b,d,f,h: shown in Photo-degradation of organic dyes (MO,MR,MB and AR) with $\mathrm{Cr}_{2} \mathrm{O}_{3} \mathrm{NPs}$ 


\section{Conclusion}

In this study, chromia $\left(\mathrm{Cr}_{2} \mathrm{O}_{3}\right)$ nanoparticles have been successfully synthesized via the plant parts mediated green synthesis. The prepared $\mathrm{Cr}_{2} \mathrm{O}_{3}$ nanoparticles are good candidate material for UV-light emitter using nanoparticle and in optical storage systems. The average particles size of the synthesized samples was confirmed by using the DLS, XRD, SEM with EDS and TEM analyses. The morphology was studied by SEM and TEM analyses, which indicates the irregular shape of $\mathrm{Cr}_{2} \mathrm{O}_{3}$ nanoparticles observed. And also the report photo-catalytic activity of green synthesized $\mathrm{Cr}_{2} \mathrm{O}_{3}$ nanoparticles, the $\mathrm{Cr}_{2} \mathrm{O}_{3}$ nanoparticles explore their potential application in dye and textile industries. The high photon capturing ability of $\mathrm{Cr}_{2} \mathrm{O}_{3}$ targets them as a potential candidate for environmental application. The Photo degradation of the four organic dyes to shown methyl orange shortly degraded compared with other three organic dyes. Photo- degradation is lower rate of the reaction in direct sunlight irradiation comparing UV light irradiation.

\section{Reference}

[1] M.A.Farook and M.H.S Mohamed., . Citrus limon Leaf extract mediated synthesis of Titanium Dioxide Nanoparticles. Life Science Archives Life Sci Archi. 3,7(2017) 901-908.

[2] W. Mertz, Chromium occurrence and function in biological systems. Physiol Rev. 49(1969) 163-239.

[3] Y.Hertz, Z.Mader, B.Hepher, A.Gertler. Glucosemetabolism in the common carp (Cyprinus carpio L.): the effect of cobalt and chromium.Aquaculture, 76(1989) 255267.

[4] W.Rosebrough, N.C.Steel, Effect of supplemental dietary chromiumornicoticacidoncarbohydratemetabolismduringbasal, starvation and refeeding periods in poultry Poult Sci. 60 (1981) 407-411.

[5] S.Okada, M.Suzuki, H.Ohba, Enhancement of ribonucleic acid synthesis on chromium (III) in mouse liver J Inorg Biochem. 19 (1983) 95-100.

[6] H.Ohba, Y.Suketa, S.Okada,. J Inorg Biochem. Enhancement of in vitro ribonucleic acid synthesis on chromium (III)-bound chromatin., 27 (1986)179-189.

[7] R.Anderson., San Diego, Chromium. In: Mertz M (ed)Traceelements in human and animal nutrition, 5th edn. Academic Press Inc (1987) 225-244 ISBN 9780080924687.

[8] R.I.Press, J.Geller, G.W.Evans, The effect of chromium picolinate on serum cholesterol and apolipoprotein fractions in human subjects., West J Med. 152 (1990) 41-45.

[9] M.F.McCarty, The case for supplemental chromium and a survey of clinical studies with chromium picolinate., J Appl Nutr. 43 (1991) 58-66.

[10] W.Mertz, Chromium in human nutrition: a review. J Nutr. 123 (1993) 626-633.

[11] M.Navarro-Alarcon, F.Gil Hernández, A.Gil Hernandez, Selenium, manganese, chromium, molybdenum, iodine and other minor trace elements.In:GilHernández A(ed) Treatiseonnutrition VolumeI: physiological and biochemical bases of nutrition Madrid . Medical Action, Spain, (2005). 997-1036

[12] M.Valko, H.Morris, M.T.Cronin, Metals, toxicity and oxidative stress., Curr Med Chem.12 (2005) 1161-1208.

[13] V.I.Lushchak, Oxidative stress as a component of transition metal toxicity in fish. In: Svensson EP (ed) Aquatic toxicology research focus Nova Science Publishers Inc., Hauppauge, (2008) 1-29.

[14] A.Piotrowska, K.Mlyni, A.Siwek, Dybala M, Opoka W, Poleszak E, Nowak G. 'Antidepressant-like effect of chromium chloride in the mouse forced swim test: 
involvement of glutamatergic and serotonergic receptors' Pharmacol Rep. 60 (2008) 991-995.

[15] D.Bagchi, S.J.Stohs, B.W.Downs, M.Bagchi, H.G.Preuss, Cytotoxicity and oxidative mechanisms of different forms of chromium., Toxicology. 180 (2002) 5-22.

[16] D.J.Opperman, L.A.Piater, E.Van Heerden, A novel chromate reductase from Thermus scotoductus SA-01 related to old yellow enzyme.J Bacteriol1. 190(2008) 3076-3082.

[17] M.D.Stout, R.A.Herbert, G.E.Kissling, B.JCollins, G.S.Travlos, K.L.Witt, R.LMelnick, K.M.Abdo, D.E.Malarkey, M.J.Hooth, Hexavalent chromium is carcinogenic to F344/N rats and B6C3F1 mice after chronic oral exposure., Environ Health Perspect.117 (2009) 716-722.

[18] A.Arillo, F.Melodia, Protective effect of fish mucus against $\mathrm{Cr}(\mathrm{VI})$ pollution, Chemosphere. 20 (1990) 397-402.

[19] X. Chang, P.G. Alderson and C.J. Wright, L. De Martino, V. De Feo and F. Nazzaro, Molecules, 14, 4213 (2009). J. Horticult. Forestry, 1 (2009) 27-31.

[20] L. De Martino, V. De Feo and F. Nazzaro, Chemical Composition and in Vitro Antimicrobial and Mutagenic Activities of Seven Lamiaceae Essential Oils,Molecules, 14 (2009) 4213-4230.

[21] M. Özcani and J.-C. Chalchat,. Essential oil composition of Ocimum basilicum L. and Ocimum minimum L. in Turkey. Czech, J. Food Sci. 20 (2002) 223-228.

[22] M.B. Hassanpouraghdam, A. Hassani and M.S. Shalamzari, Menthone and estragole rich essential oil of cultivated Ocimum basilicum L. from Northwest Iran, Chemija, 21 (2010) 59-62.

[23] M.B. Hassanpouraghdam, G.R. Gohari, S.J. Tabatabae and M.R. Dadpour, Inflorescence and leaves essential oil composition of hydroponically grown Ocimum basilicum L. J. Serb.

Chem. Soc., 75 (2010) 1361-1368.

[24] S.J. Lee, K. Umano, T. Shibamoto and K.-G. Lee, Identification of volatile components in basil (Ocimum basilicum L.) and thyme leaves (Thymus vulgaris L.) and their antioxidant properties,Food Chem. 91 (2005) 131-137.

[25] I.H.N. Bassolé, A. Lamien-Meda, B. Bayala, S. Tirogo, C. Franz, J. Novak, R.C. Nebié and M.H. Dicko, Composition and antimicrobial activities of Lippia multiflora Moldenke, Mentha x piperita L. and Ocimum basilicum L. essential oils and their major monoterpene alcohols alone and in combination Molecules, 15 (2010) 78257839.

[26] A.I. Hussain, F. Anwar, S.T.H. Sherazi and R. Przybylski, Chemical composition, antioxidant and antimicrobial activities of basil (Ocimum basilicum) essential oils depends on seasonal variations., Food Chem., 108 (2008) 986-995.

[27] S.E. Sajjadi, Analysis of the Essential Oils of Two Cultivated Basil (Ocimum basilicum) from Iran.,DARU, 14 (2006) 128-130.

[28] S.R. Vani, S.F. Cheng and C.H. Chuah, Comparative Study of Volatile Compounds from Genus Ocimum, Am. J. Appl. Sci., 6 (2009) 523-528.

[29] T. Satgurunathan, P.S. Bhavan and R. D. Sherin Joy, Green Synthesis of Chromium Nanoparticles and Their Effects on the Growth of the Prawn Macrobrachium rosenbergii Post-larvae, Biological Trace Element Research https://doi.org/10.1007/s12011-018-1407-X

[30] Z. Ahmad, A. Shamim, S. Mahmood, T. Mahmood, F. Ullah Khan, Biological Synthesis and Characterization of Chromium (iii) oxide nanoparticles, Eng. Appl. Sci. Lett., 1 (2018) $23-29$. 
[31] M. Nilavukkarasi, S. Vijayakumar, S. Prathipkumar., Capparis zeylanica mediated bio-synthesized $\mathrm{ZnO}$ nanoparticles as antimicrobial, photocatalytic and anti-cancer applications, Mat Sci En Tech, 3 (2020) 335-343.

[32] M. Kgatle, K. Sikhwivhilu, G. Ndlovu and N. Moloto . Degradation Kinetics of Methyl Orange Dye in Water Using Trimetallic Fe/Cu/Ag Nanoparticles ,Catalysts. 11 (2021) 428.

[33] E. D. Mohamed Isa, K. Shameli, H. J. Ch'ng, N. W. Che Jusoh, R. Hazan, Photocatalytic degradation of selected pharmaceuticals using green fabricated zinc oxide nanoparticles., Adv Powder Tech. 32 (2021) 2398-2409.

[34] G. Vanitha, R. Manikandan, A. Pragasam, K. Sathiyamoorthi, B. Dhinakaran., EcoFriendly Synthesis of some Novel Metal Nanoparticles Mediated by Ocimum Basilicum-Lamiaceae ( Thiru Neetru Pathilai) Leaves Extract.,IJRASET., 9 (2021) 548-561.

[35] S.A. Khan, S.Shahid, C.S. Lee, Green Synthesis of Gold and Silver Nanoparticles Using Leaf Extract of Clerodendrum inerme; Characterization, Antimicrobial, and Antioxidant Activities., Biomolecules. 10 (2020) 835-860.

[36] S.A. Khan, S. Shahid, B.Shahid, U.Fatima, S.A. Abbasi, Green Synthesis of MnO Nanoparticles Using Abutilon indicum Leaf Extract for Biological, Photocatalytic, and Adsorption Activities., Biomolecules, 10 (2020) 785-804

[37] J. Iqbal, A.Munir, S.Uddin, Facile green synthesis approach for the production of chromium oxide nanoparticles and their different in vitro biological activities Microsc. Res. Tech. 83 (2020) 706-719.

[38] H.E.Ahmed Mohamed, S. Afridi, A.T.Khalil, T. Zohra, M. Ali, M.M.Alam, A.Ikram, Z.K.Shinwari, M. Maaza,. Phyto fabricated Cr2O3 nanoparticle for multifunctional biomedical applications, Nanomedicine 15(2020) 1653-1669.

[39] T. Khalafi, F. Buazar, K. Ghanemi, Phycosynthesis and enhanced photocatalytic activity of zinc oxide nanoparticles toward organosulfur pollutants. Sci. Rep. 9(2019) $1-10$.

[40] L. Chen, Z. Song, X.Wang, S.V. Prikhodko, J. Hu, S. Kodambaka, R. Richards,. Three-dimensional morphology control during wet chemical synthesis of porous chromium oxide spheres., ACS Appl. Mater. Interfaces, 1(2009) 1931-1937.

[41] G. Hao, L. Xiao, Y. Hu, F. Shao, X. Ke, J. Liu, F. Li, W. Jiang, F.Zhao, H. Gao, Facile preparation of $\mathrm{Cr} 2 \mathrm{O} 3$ nanoparticles and their use as an active catalyst on the thermal decomposition of ammonium perchlorate., J. Energ. Mater. 37 (2019), 251269.

[42] U.R. Sharma, N. Sharma, Green synthesis, anti-cancer and corrosion inhibition activity of $\mathrm{Cr}_{2} \mathrm{O}_{3}$ nanoparticles, Bioint Res. App. Chem. 111 (2021) 8402-8412.

[43] J. Iqbal, B.A. Abbasi, A. Munir, S. Uddin, S. Kanwal, T. Mahmood, Facile green Synthesis approach for the production of chromium oxide nanoparticles and their different in vitro biological activities Microsc. Res. Tech. 836 (2020) 706-719.

[44] G.Dong, Y.Wang, L.Gong, M.Wang, H.Wang, N.He, Y.Zheng, Q.Li, Formation of soluble $\mathrm{Cr}(\mathrm{III})$ end-products and nanoparticles during $\mathrm{Cr}(\mathrm{VI})$ reduction by Bacillus cereus strain XMCr-6., Biochem Eng J. 70 (2013)166-172.

[45] M.M. Alnuaimi, M.A. Rauf, S.S. Ashraf, Comparative degradation study of Neutral Red by different oxidative processes., Dyes Pigm. 72 (2007) 367-371.

[46] J.H. Sun, S.P. Sun, G.L. Wang, L.P. Qiao, Degradation of azo dye Amido black 10B in aqueous solution by Fenton oxidation process.,Dyes Pigm. 74 (2007) 647-652.

[47] D.H. Bremner, R. Molina, F. Martinez, J.A. Melero, Y. Segura, Degradation of phenolic aqueous solutions by high frequency sono-Fenton systems (US- $\mathrm{Fe}_{2} \mathrm{O}_{3} / \mathrm{SBA}-$ 15- $\mathrm{H}_{2} \mathrm{O}_{2}$ ).,Appl. Catal. B: Environ. 90 (2009) 380-388. 
[48] G. Moussavi, M. Mahmoudi, Degradation and Biodegradability Improvement of the Reactive Red 198 Azo Dye Using Catalytic Ozonation with MgO Nanocrystals, Chem. Eng. J. 152 (2009) 1-7.

[49] R.Vinayagam, R.Selvaraj, P.Arivalagan, and T.Varadavenkatesan, Synthesis, characterization and photocatalytic dye degradation capability of Calliandra haematocephala-mediated zinc oxide nanoflowers. J. Photochem. Photobiol. B: Biol. 203, (2020) 111760-.

[50] S. Caudo, G. Centi, C. Genovese, S. Perathoner, Homogeneous versus heterogeneous catalytic reactions to eliminate organics from waste water using $\mathrm{H} 2 \mathrm{O} 2$ Top. Catal. 40 (2006) 207-219.

[51] P. Bautista, A.F. Mohedano, J.A. Casas, J.A. Zazo, J.J. Rodriguez, An Overview of the Application of Fenton Oxidation to Industrial Wastewaters Treatment J. Chem. Technol. Biotechnol. 83 (2008) 1323-1338.

[52] A.Haider, M. Ijaz, S.Ali, J.Haider, M.Imran, H.Majeed and M.Ikram, Green synthesized phytochemically (Zingiber officinale and Allium sativum) reduced nickel oxide nanoparticles confirmed bactericidal and catalytic potential. Nanoscale Res. Lett. 15 (1),(2020) 1-11

[53] H. Habazaki, Y. Hayashi, H. Konno, characterization of electrodeposited $\mathrm{WO}_{3}$ film and its application to electrochemical wastewater treatment, Electrochim. Acta 47 (2012) 4181-4188.

[54] A.Naseer, S.Nosheen, S.Kiran, S.Kamal, M.A. Javaid, M.Mustafa, and A. Tahir, Degradation and detoxification of Navy Blue CBF dye by native bacterial communities: an environmental bioremedial approach. Desalin. Water Treat. 57 (50), (2016) 24070-24082..

[55] M. Amini, B. Pourbadiei, T. Purnima A. Ruberu, L. Keith Woo, Catalytic activity of MnOx/WO3 nanoparticles: synthesis, structure characterization and oxidative degradation of methylene blue.., New J. Chem. 38 (2014) 1250-1255.

[56] J. Cao, Y. Zhu, L. Shi, L. Zhu, K. Bao, S. Liu, Y. Qian, Double shelled Mn2O3 hallow sphere and their application in water treatment, Eur. J. Inorg. Chem. 2010 (2010) 1172-1176.

[57] J. Zhao, Z. Tao, J. Liang, J. Chen, Facile synthesis of nanoporous $\gamma$-MnO2 structures and their application in rechargeable Li-ion batteries. Cryst. Growth Des. 8 (2008) 2799-2805.

[58] T. Yu, J. Moon, J. Park, Y.I. Park, H.B. Na, B.H. Kim, I.C. Song, W.K. Moon, T. Hyeon, Various-shaped uniform $\mathrm{Mn} 3 \mathrm{O} 4$ nanocrystals synthesized at low temperature in air atmosphere, Chem. Mater. 21 (2009) 2272-2279.

[59] Y. Ding, C. Hou, B. Li, Y. Lei, Sensitive hydrazine detection using a porous Mn2O3 nanofibers-based sensor., Electroanalysis 23 (2011) 1245-1251.

[60] M. Amini, H. Naslhajian, S.M.F. Farnia, V-doped titanium mixed oxides as efficient catalysts for oxidation of alcohols and olefins., New J. Chem. 38 (2014) 1581-1586.

[61] S.S. Shinde, P.S. Shinde, C.H. Bhosale, K.Y. Rajpure, Zinc oxide mediated heterogeneous photocatalytic degradation of organic species under solar radiation J. Photochem. Photobiol. B: Biol. 104 (2011) 425-433.

[62] S.S. Shinde, C.H. Bhosale, K.Y. Rajpure, Photocatalytic activity of sea water using TiO2 catalyst under solar light., J. Photochem. Photobiol. B: Biol. 103 (2011) 111117.

[63] P. Amornpitoksuk, S. Suwanboon, S. Sangkanu, A. Sukhoom, J. Wudtipan, K. Srijan, S. Kaewtaro, Synthesis, photocatalytic and antibacterial activities of $\mathrm{ZnO}$ particles modified by diblock copolymer., Power Tech. 212 (2011) 432-438. 
[64] J.Rueda Márquez, I. Levchuk, and M.J.C.Sillanpää, Application of catalytic wet peroxide oxidation for industrial and urban wastewater treatment: a review. Catalysts 8, (2018) 673-681. doi: 10.3390/catal8120673

[65] J.H. Sun, S.Y. Dong, Y.K. Wang, S.P. Sun, Preparation and photocatalytic property of a novel dumbbell-shaped $\mathrm{ZnO}$ microcrystal photocatalyst., J. Hazard. Mater. 172 (2009) 1520-1526.

[66] Y. Wang, L. Liu, L. Xu, X. Cao, X. Li, Y. Huang, C. Meng, Z. Wang, W. Zhu, $\mathrm{Ag} 2 \mathrm{O} / \mathrm{TiO} 2 / \mathrm{V} 2 \mathrm{O} 5$ one-dimensional nanoheterostructures for superior solar light photocatalytic activity., Nanoscale 6 (2014) 6790-6797.

[67] N.A.Youssef, S.A.Shaban, F.A.Ibrahim and A.S.Mahmoud, Degradation of methyl orange using Fenton catalytic reaction. Egypt. J. Pet. 25, (2016). 317-321.

[68] X.Fuku, K. Kaviyarasu, N.Matinise, M.Maaza, Punicalagin green functionalized $\mathrm{Cu} / \mathrm{Cu}_{2} \mathrm{O} / \mathrm{ZnO} / \mathrm{CuO}$ nanocomposite for potential electrochemical transducer and catalyst .,Nanoscale Res. Lett. 11(2016) 386-398.

[69] K. Singh and S. Arora, "Removal of synthetic textile dyes from wastewaters: A critical review on present treatment technologies,"Critical Reviews in Environmental Science and Technology., 41, (2011) 807-878,.

[70] S. Thota, S. Tirukkovalluri, and S. Bojja, Visible Light Induced Photocatalytic Degradation of Methyl Red with Codoped Titania., Jr Catalysis. 10(2014) 1-7.

[71] M. Rauf and S. S. Ashraf, "Fundamental principles and application of heterogeneous photocatalytic degradation of dyes in solution," Chemical engineering journal,.151, (2009) 10-18,.

[72] D.B. Bharti, A.V. Bharati., Photocatalytic degradation of Alizarin Red dye under visible light using $\mathrm{ZnO} \& \mathrm{CdO}$ nanomaterial, Optik 160 (2018) 371-379

[73] M. Nazim, A. A. P. Khan, A. M. Asiri, and J. H. Kim, Exploring Rapid Photocatalytic Degradation of Organic Pollutants with Porous CuO Nanosheets: Synthesis, Dye Removal, and Kinetic Studies at Room Temperature ACS Omega. 6 (2021) 2601-2612

[74] K.Li, J.Lu, X. Zheng, Q.Lian, Three-dimensional hierarchical superstructures of CuO nano flowers: Facile synthesis and applications for enhanced photocatalytic activity of dyes., Russian J. Appl. Chem. 92 (2019) 71-77.

[75] S.J Bransfield, D.M. Cwiertny, K. Livi, D.H.Fairbrother, Influence of transition metal additives and temperature on the rate of organohalide reduction by granular iron: Implications for reaction mechanisms., Appl. Catal. B Environ. 76 (2007) 348356.

[76] Y.Wang, H. Zhao, G. Zhao, Iron-copper bimetallic nanoparticles embedded within ordered mesoporous carbon as effective and stable heterogeneous Fenton catalyst for the degradation of organic contaminants., Appl. Catal. B Environ. 164(2015) 396406.

[77] S.Mossa Hosseini, B. Ataie-Ashtiani, M.Kholghi, M. Nitrate reduction by nano-Fe/Cu particles in packed column Desalination. 276(2011) 214-221.

[78] J.Wang, C. Liu, J.Li, R.Luo, X.Hu, X.Sun, J.Shen, W.Han, L.Wang, In-situ incorporation of iron-copper bimetallic particles in electrospun carbon nanofibers as an efficient Fenton catalyst .,Appl. Catal. B Environ.207(2017) 316-325.

[79] J.Wang, C.Liu, L.Tong, J.Li, R.Luo, J.Qi, Y.Li, L.Wang, Iron-copper bimetallic nanoparticles supported on hollow mesoporous silica spheres: An effective heterogeneous Fenton catalyst for orange II degradation,. RSC Adv.5(2015) 5, 69593-69605

[80] Y.Badr, M.G.Abd El-Wahed and M.A.Mahmoud. Photocatalytic degradation of methyl red dye by silica nanoparticles, J. Hazard. Mater. 154 (2008) 245-253. 
[81] M. Saghi, A. Shokri1, A. Arastehnodeh, M. Khazaeinejad, A. Nozari., The photo degradation of methyl red in aqueous solutions by $\alpha-\mathrm{Fe}_{2} \mathrm{O}_{3} / \mathrm{SiO}_{2}$ nano photocatalyst $\mathrm{J}$. Nanoanalysis.,5 3 (2018) 163-170.

[82] J.Pal, M.Ganguly, S.Dutta, C.Mondal, Y.Negishi, T.Pal, . Hierarchical Au-CuO Nanocomposite from Redox Transformation Reaction for Surface Enhanced Raman Scattering and Clock Reaction., Cryst EngComm. 16 (2014) 883-893.

[83] R.Comparelli, E.Fanizza, M.L.Curri, P.D.Cozzoli , G.Mascolo and A. Agostiano. UV-induced photocatalytic degradation of azo-dyes by organiccapped $\mathrm{ZnO}$ nanocrystals immobilized onto substrates., Appl. Catal. B: Environ. 60 (2005) 1-11.

[84] C.L.Buitron, M.Quezada and G. Moreno. Aerobic degradation of the azo dye acid red in a sequencing batch bio-filter. Bioresource Technol. 92 (2004) 143-149.

[85] S.Sakthivel, M.V.Shankar and M.Palanichamy, Enhancement of photocatalytic activity by metal deposition: characterisation and photonic efficiency of Pt,AuandPddeposited onTiO2 catalyst WaterRes. 38 (2004) 3001-3008.

[86] M.A.Mahmoud, A.Poncheri, Y. Badr, and M.G.AbdElWaned, Photocatalytic degradation of methyl red dye," South Afri Jr of Sci, vol. 105 (2009) 299-303.

[87] F. M. D. Chequer, G. A. R. Oliveira, E. R. A. Ferraz, J. Carvalho, M. V. B. Zanoni, and D. P. Oliveir, "Textile dyes: Dyeing process and environmental impact," 2013.

[88] M. Constapel, M. Schellentrager, J. M. Marzinkowski, and S. Gab, "Degradation of reactive dyes in wastewater from the textile industry by ozone: analysis of the products by accurate masses," Water Res. 43(2009) 733-743.

[89] M. Rauf and S.S. Ashraf, "Fundamental principles and application of heterogeneous photocatalytic degradation of dyes in solution,"Chemical engineering journal. 151(2009) 10-18.

[90] N.Joseph, K.Vellayan, B.González, M.A.Vicente, A.Gil, ''Effective degradation of methylene blue in aqueous solution using $\mathrm{Pd}$ supported $\mathrm{Cu}$-doped Ti-pillared montmorillonite catalyst' Appl. Clay Sci.168(2019)7-10.

[91] M.F.Samsudin, S.Sufian, R.Bashiri, N.M.Mohamed, L.T.Siang, R.M.Ramli, Optimization of photodegradation of methylene blue over modified TiO2/BiVO4 photocatalysts: Effects of total TiO2 loading and different type of co-catalyst., Mater. Today Proc. 5 (2018) 21710-21717.

[92] M.Khaksar, M. Amini, D.M.Boghaei, K.H. Chae, S.Gautam, Mn-doped ZrO2 nanoparticles as an efficient catalyst for green oxidative degradation of methylene blue., Catal. Commun. 72 (2015) 1-5.

[93] L.Kong, Z.Diao, X.Chang, D.Chen. Synthesis of recoverable and reusable granular $\mathrm{MgO}-\mathrm{SCCA}-\mathrm{Zn}$ hybrid ozonation catalyst for degradation of methylene blue. J. Environ. Chem. 4 (2016) 4385-4391.

[94] M.Abbas, B.P.Rao, V. Reddy, C. Kim, Fe3O4/TiO2 core/shell nanocubes: Singlebatch surfactantless synthesis, characterization and efficient catalysts for methylene blue degradation Ceram. Int. 40 (2014) 11177-11186.

[95] D.D.Mishra, G. Tan, Visible photocatalytic degradation of methylene blue on magnetic $\mathrm{Sr}_{12} \mathrm{FeO}_{19}$ J. Phys. Chem. Solids. 123 (2018) 157-161.

[96] J.T.Adeleke, T.Theivasanthi, M.Thiruppathi, M.Swaminathan, T. Akomolafe, A.B. Alabi, Photocatalytic degradation of methylene blue by $\mathrm{ZnO} / \mathrm{NiFe}_{2} \mathrm{O}_{4}$ nanoparticles., Appl. Surf. Sci. 455 (2018) 195-200.

[97] D.Huang, J.Ma, C.Fan, K.Wang, W.Zhao, M.Peng, S.Komarneni,. Co-Mn-Fe complex oxide catalysts from layered double hydroxides for decomposition of methylene blue: Role of Mn Appl. Clay Sci. 152 (2018) 230-238.

[98] R.S.Ganesh, E.Durgadevi, M.Navaneethan, S.K.Sharma, H.S.Binitha,S.Ponnusamy, C.Muthamizhchelvan, Y.Hayakawa, Visible light induced photocatalytic degradation 
of methylene blue and rhodamine B from the catalyst of CdS nanowire Chem. Phys. Lett. 684 (2017) 126-134.

[99] G.Liao, Q.Li, W.Zhao, Q.Pang, H.Gao, Z.Xu,. In-situ construction of novel silver nanoparticle decorated polymeric spheres as highly active and stable catalysts for reduction of methylene blue dye Appl. Catal. A Gen. 549(2018) 102-111.

[100] S.Veziroglu, M. Kuru, M.Z.Ghori, F.K.Dokan, A.M. Hinz, T.Strunskus, F.Faupel, O.C.Aktas, Ultra-fast degradation of methylene blue by $\mathrm{Au} / \mathrm{ZnO}-\mathrm{CeO} 2$ nano-hybrid catalyst., Mater. Lett. 209 (2017) 486-491.

[101] J.Sun, H.Lu, L. Du, H.Lin, H.Li,. Anodic oxidation of anthraquinone dye Alizarin Red S at Ti/BDD electrodes. Appl. Surf. Sci. 257 (2011) 6667-6671.

[102] K.Joshi, V.Shrivastava, Degradation of alizarine red-S (A textiles dye) by photocatalysis using $\mathrm{ZnO}$ and $\mathrm{TiO} 2$ as photocatalyst., Int. J. Environ. Sci. 2 (2011) 821.

[103] S. K. Kansal, R. Lamba, S. Mehta, A. Umar, Photocatalytic degradation of Alizarin Red S using simply synthesized ZnO nanoparticles Mater. Lett. 106 (2013) 385-389.

[104] B.Lai, Y.Zhou, J.Wang, Z.Yang, \& Z.Chen, Application of excitation and emission matrix fluorescence (EEM) and UV-vis absorption to monitor the characteristics of Alizarin Red S (ARS) during electro-Fenton degradation process Chemosphere. 9311 (2013) 2805. 